\title{
REVIEW
}

\section{Role of the tumor microenvironment in digestive neuroendocrine tumors}

\author{
Thomas Cuny ${ }^{1,2,3}$, Wouter de Herder ${ }^{1}$, Anne Barlier ${ }^{2,3}$ and Leo J Hofland ${ }^{1}$ \\ 1Division Endocrinology, Department of Internal Medicine, Erasmus Medical Center, Rotterdam, The Netherlands \\ ${ }^{2}$ Aix-Marseille Université, Institut National de la Santé et de la Recherche Médicale (INSERM), U1251, Marseille Medical Genetics (MMG), Marseille, France \\ 3Department of Endocrinology, Assistance Publique - Hôpitaux de Marseille (AP-HM), Hôpital de la Conception, Centre de Référence des Maladies Rares \\ Hypophysaires HYPO, Marseille, France
}

Correspondence should be addressed to L J Hofland: I.hofland@erasmusmc.nl

\begin{abstract}
Gastroenteropancreatic neuroendocrine tumors (GEP-NETs) represent a group of heterogeneous tumors whose incidence increased over the past few years. Around half of patients already present with metastatic disease at the initial diagnosis. Despite extensive efforts, cytotoxic and targeted therapies have provided only limited efficacy for patients with metastatic GEP-NETs, mainly due to the development of a certain state of resistance. One factor contributing to both the failure of systemic therapies and the emergence of an aggressive tumor phenotype may be the tumor microenvironment (TME), comprising dynamic and adaptative assortment of extracellular matrix components and nonneoplastic cells, which surround the tumor niche. Accumulating evidence shows that the TME can simultaneously support both tumor growth and metastasis and contribute to a certain state of resistance to treatment. In this review, we summarize the current knowledge of the TME of GEP-NETs and discuss the current therapeutic agents that target GEP-NETs and those that could be of interest in the (near) future.
\end{abstract}
Key Words
- neuroendocrine tumors
- microenvironment
- angiogenesis
- growth factors

\section{Introduction}

Human gastroenteropancreatic neuroendocrine tumors (GEP-NETs) represent a heterogeneous group of tumors emerging from cells producing glycopeptides and biogenic amines (Klöppel 2011). They account for approximately $0.5 \%$ of all human cancers (Modlin et al. 2008, Lawrence et al. 2011, Hallet et al. 2014, Dasari et al. 2017). Pancreatic neuroendocrine tumors (PNETs) represent around $10 \%$ of the neuroendocrine tumors (NETs) seen in the clinic, while the distributions of small intestine neuroendocrine tumors (SI-NETs) and rectal NETs differ between region of the world, genders and ethnicities (Fig. 1) (Hauso et al. 2008, Yao et al. 2008, Ito et al. 2010, Landerholm et al. 2010, Taghavi et al. 2013, Hallet et al. 2014).
The current treatment of GEP-NETs consists of a multimodal approach. Surgery remains, if feasible, the first therapeutic option that can result in a complete cure of the disease (Partelli et al. 2017). Besides surgery, locoregional treatment, chemo- and/or radiotherapy, as well as targeted therapies, represent alternative options, which are generally discussed in a case-by-case approach (O'Toole et al. 2016). The medical treatments are primarily represented by long-acting somatostatin analogs (SSAs, octreotide long-acting release (LAR) and lanreotide Autogel), mTOR (mammalian target of rapamycin) inhibitors and sunitinib malate, an inhibitor of platelet-derived growth factor (PDGF) and vascular endothelial growth factor (VEGF) receptors. 


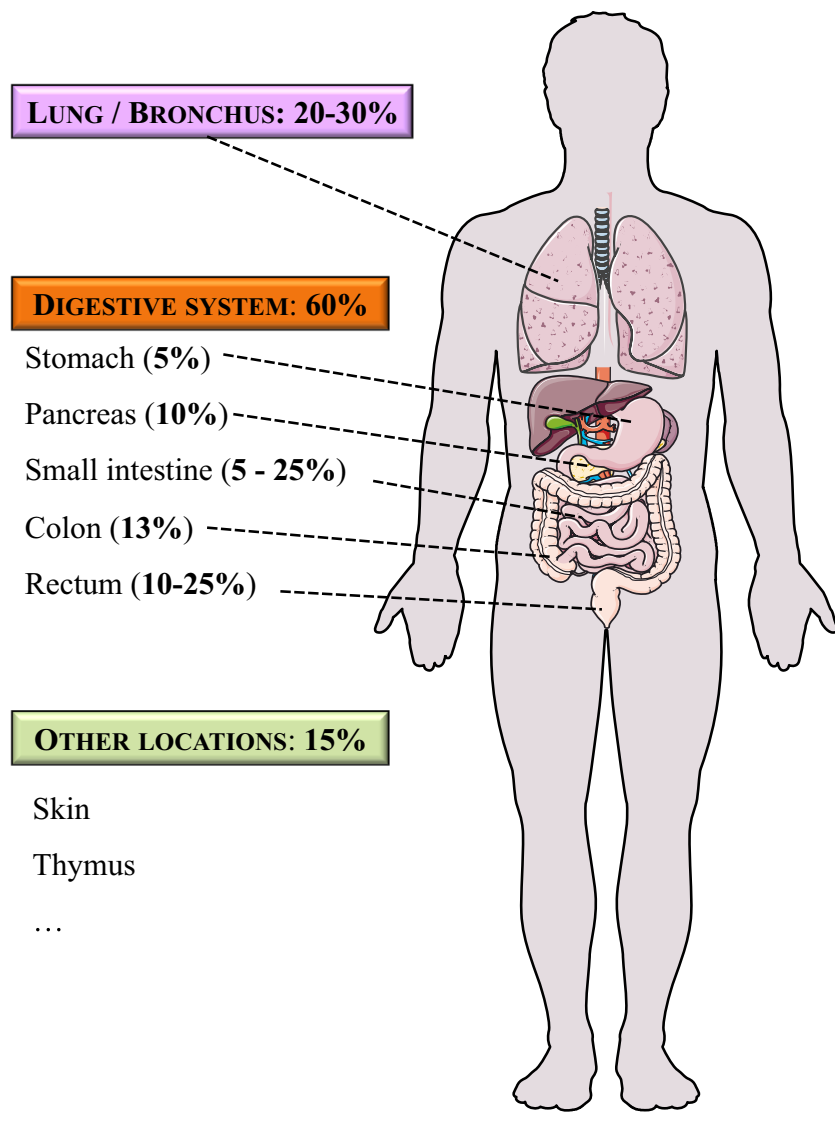

Figure 1

Schematic distribution of neuroendocrine tumors in the human body. Based on the compilation of data from Hauso et al. (2008), Yao et al. (2008), Ito et al. (2010), Landerholm et al. (2010), Taghavi et al. (2013), Hallet et al. (2014).

In spite of the substantial progress that has been made in the early diagnosis and the therapeutic management of GEP-NETs, about half of the patients already present metastasis, mainly in the liver, at the initial diagnosis or develop metastases during the follow-up (Hallet et al. 2014, Dasari et al. 2017). The limited in vivo efficacy of targeted therapies to inhibit tumor progression or to induce tumor stabilization strikingly contrasts with their efficacy in vitro in experimental models (Kulke 2007). Such a discrepancy may, at least partially, arise from influences exerted by the direct microenvironment surrounding the tumor, referred to as the tumor microenvironment (TME) (Ungefroren et al. 2011).

The TME is a complex nebula comprising multiple cell types, supportive matrix and soluble factors, which promotes the tumor growth and influence tumor behavior (Hanahan \& Weinberg 2011). Whereas it appears to be highly specific from one tumor type to another, recent studies underline the critical role played by the TME in the induction of a tumor 'resistance to treatment' behavior, either via soluble factors released within the TME (Straussman et al. 2012) or due to the physical barrier formed by the tumor stroma, which can hamper drug delivery (Olive et al. 2009, Jacobetz et al. 2013). There are also several lines of evidence that the metastatic process can be the consequence of molecular interactions and dysregulation of mechano-reciprocity between the tumoral cells and their microenvironment (Butcher et al. 2009, Ungefroren et al. 2011).

Until now, the role of the TME in GEP-NETs is underexposed, even though it may constitute both a key driver of tumor growth and a critical modulator of the response to treatment. Identifying new therapeutic targets within the TME or establishing novel therapeutic strategies, such as the so-called co-targeting approach, is a key point to improve the management of such tumors.

\section{Angiogenesis: a common feature in the microenvironment of neuroendocrine tumors}

\section{Molecular basis of angiogenesis in GEP-NETs}

NETs are characterized by a high vascular supply owing to the histological organization of endocrine glands with fenestrated epithelium lining the blood vessels to facilitate hormone secretion and dumping into the bloodstream (Turner et al. 2003, Scoazec 2005).

In adult life, angiogenesis occurs through two fundamental mechanisms: the growth of new vessels from capillaries and the enlargement of pre-existing collateral vessels, also known as adaptative arteriogenesis (Risau 1997). In GEP-NETs, a permanent vascular supply is ensured through the formation of new blood vessels from existing ones by a multistep process involving multiple angiogenic factors that are simultaneously counterbalanced by antiangiogenic molecules (Fig. 2). Among proangiogenic factors, VEGF also referred to VEGF-A, is the best known and characterized (Ferrara 2004). Its action is mediated through binding to two highly related tyrosine kinase receptors, VEGFR-1 and VEGFR-2, which are predominantly restricted to endothelial cells where they promote angiogenesis once activated (Kanno et al. 2000), as demonstrated in vitro by a VEGF-induced formation of endothelial fenestrae (Esser et al. 1998). On the other hand, an effective inhibition of the VEGF signaling resulted in a striking decrease of vascular density (Inai et al. 2004), an effect rapidly reversed by discontinuation of VEGF inhibition (Mancuso et al. 2006).

In human GEP-NETs, the VEGF/VEGFR system is, generally speaking, overexpressed compared to the 


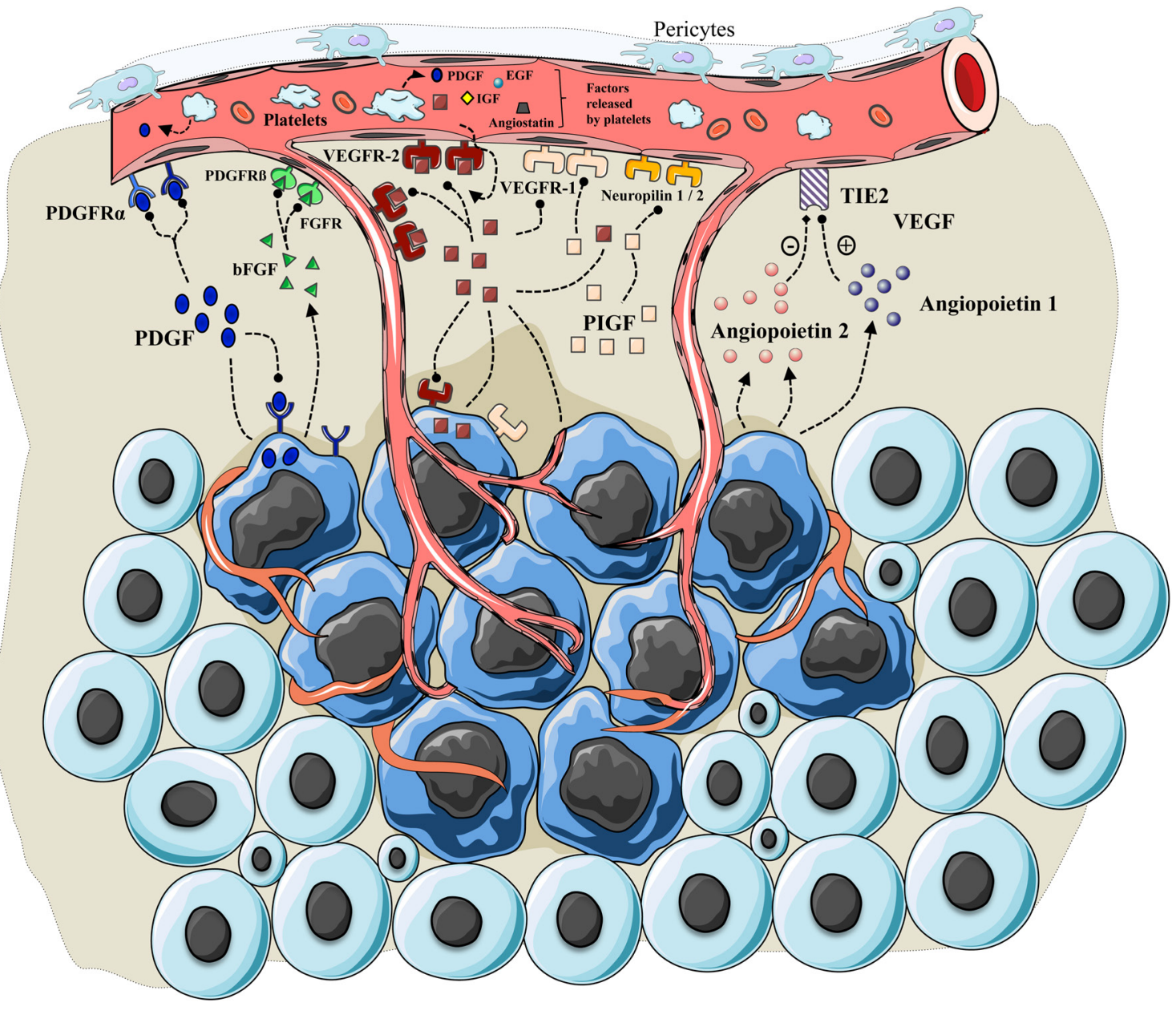

Figure 2

Schematic representation of angiogenesis in GEP-NETs and the main molecular factors that regulate it, as described in this review.

normal tissue (Turner et al. 2003). In contrast to the normal pancreas, where expression of VEGF is limited to particular endocrine cells, such as the gastrin-secreting cells or the pancreatic polypeptide-secreting cells in the islets of Langerhans (Kuroda et al. 1995), a marked expression of VEGF has been observed by immunohistochemistry in human GEP-NETs (Itakura et al. 2000, La Rosa et al. 2003). Around $50-80 \%$ of PNETs are immunopositive for VEGF with a strong immunoreactivity observed in the tumoral cell compartment (Kuroda et al. 1995, Terris et al. 1998, La Rosa et al. 2003, Angelescu et al. 2013). The corresponding receptors, VEGFR-1 and -2, are detected in both the tumoral compartment and the surrounding endothelial cells, which suggest an autocrine/paracrine action of VEGF such as the one described in human pancreatic adenocarcinomas (von Marschall et al. 2000). At the biological level, higher plasma concentrations of circulating VEGF have been found in patients with metastatic GEP-NETs compared to their non-metastatic counterparts (Cigrovski Berković et al. 2016); however, this does not mean per se that VEGF is the inescapable factor that permits the tumor cells to metastasize. Animal studies conducted in the PNET-predisposing RipTag2 mouse model, albeit far from human observations, also showed that upregulation of VEGF was a critical step in the development of the tumor (Folkman et al. 1989, Christofori et al. 1995, Bergers et al. 1999, Inoue et al. 2002).

Other factors are indirectly involved in the process of angiogenesis and its maintenance. Among them, angiopoietin-2 (ANG-2) which binds the endothelialspecific receptor tyrosine kinase 2 (TIE2) and acts either as a negative regulator of ANG-1/TIE2 signaling during angiogenesis (Eklund \& Saharinen 2013) or, under certain conditions, as promoter of angiogenesis (Felcht et al. 2012). In human PNETs, an eight-fold upregulation 
of ANG-2 detected by microarray expression profiling, as compared to the non-tumoral pancreatic tissue, was observed (Durkin et al. 2004). Moreover, a tumor-specific immunopositivity (i.e. present in tumor and absent in surrounding normal pancreas) for ANG-2 is observed in a majority of PNETs (Durkin et al. 2004, Detjen et al. 2010). In contrast, ANG-1 and TIE2 did not show differential expression between tumor and normal pancreas (Durkin et al. 2004). These observations suggest that the ANG-2 system activation may arise during the tumorigenesis process. Experimental data using ANG-2-overexpressing human PNET cell lines BON-1 (by transfection) showed a significant development of neoangiogenesis in orthotopic NET xenografts, compared to WT BON-1 xenografts (Detjen et al. 2010). Although not used routinely as a biomarker of disease activity or aggressivity, plasma concentrations of ANG-2 are significantly higher in patients with GEP-NETs, compared to healthy controls, and even further elevated in patients with metastatic disease, compared to patients without metastasis (Srirajaskanthan et al. 2009, Detjen et al. 2010, FigueroaVega et al. 2010).

Endostatin is an endogenous peptide that inhibits the migration and proliferation of vascular endothelial cells, and recombinant human endostatin showed a significant therapeutic impact in metastatic melanomas at the clinical level (Cui et al. 2013). However, no significant tumor regression was observed following treatment with recombinant human endostatin in patients with advanced GEP-NETs (Kulke et al. 2006).

In summary, angiogenesis appears as an essential mechanism for the NET growth and maintenance, especially in well-differentiated and low-grade tumors where markers of angiogenesis are overwhelmingly found as compared to high-grade and/or undifferentiated forms of GEP-NETs, a condition known to define the 'neuroendocrine paradox' (in contrast with other models of epithelial tumors in which the highest degree of vascularization generally reflects a more aggressive tumor) (Poncet et al. 2009, Scoazec 2013, Yazdani et al. 2014). In well-differentiated NETs, it is still unknown whether marked angiogenesis increases the risk of distant metastasis. Another source of uncertainty related to angiogenesis concerns the adaptative mechanisms that occur during the antiangiogenic therapy regimen of certain patients with GEP-NETs, responsible for an escape and, ultimately, a resistance to this treatment. In the following section, we will discuss the concept of resistance to antiangiogenic therapy with regard to tumor microenvironment.

\section{Tumor microenvironment and resistance to antiangiogenic therapies in GEP-NETs}

In the setting of GEP-NETs, VEGF pathway inhibitors have shown only temporary beneficial effects at best, generally followed by a restoration of tumor growth and progression (Shojaei \& Ferrara 2008) whose mechanisms have been described on the basis of preclinical studies although not validated clinically (Bergers \& Hanahan 2008):

- A pre-existing state of resistance, also called intrinsic resistance, observed in a minority of patients with PNETs and treated with the VEGFR inhibitor, sunitinib. These patients failed to show any transient clinical benefit from the treatment, namely no tumor shrinkage, no cessation of tumor growth (stasis) and not even retardation in the growth rate (Raymond et al. 2011). In human GEP-NETs, the involvement of the TME in the intrinsic resistance to treatment possibly occurs by the local production of other-thanVEGF alternative proangiogenic signals overcoming the VEGF pathway inhibition and maintaining the angiogenic process in the tumor niche (Bergers \& Hanahan 2008) (see below).

- The second described mode of resistance to antiangiogenic therapies referred to as acquired resistance, which means that the tumor progressively became resistant to the treatment after an initial phase of sensitivity. Acquired resistance in GEP-NETs results from the activation of alternative ways that sustain tumor growth whereas the specific therapeutic target of the antiangiogenic drug remains inhibited (Bergers \& Hanahan 2008, Tijeras-Raballand et al. 2012). In GEP-NETs, one well-described mechanism of acquired resistance is the hypoxia state the tumor undertakes, directly generated by the effect of antiangiogenic therapy (Allen et al. 2011, Yao \& Phan 2011). By entering within a hypoxic state, the tumor cells released high amounts of hypoxia-inducible factor 1-alpha (HIF-1A), the master transcriptional regulator of cellular response to hypoxia (Semenza 1998). In turn, HIF-1A induces or upregulates alternate proangiogenic growth factors (TijerasRaballand et al. 2012). Apart from the synthesis of hypoxia-induced proangiogenic factors, other mechanisms contribute to the acquired resistance to antiangiogenic therapies like the increase in pericyte coverage; however, their role in the field of GEP-NETs remains to be clarified (see review: Bergers \& Hanahan 2008). 


\section{Interactions between tumor and stroma in GEP-NETs}

\section{Secretion of growth factors and cytokines within the} TME: putative role and function

Tumor cells and cells that are part of the TME, including vascular cells, stromal fibroblasts and inflammatory cells, are constantly exposed to various growth factors and cytokines that modulate tumor growth, invasiveness and metastasis (Hanahan \& Weinberg 2011). These growth factors and cytokines mostly act in a paracrine fashion on tumor cells to stimulate their proliferation, sensitivity to treatment, chemoresistance, motility, invasion, etc. Given the numerous factors that have been reported so far in the TME of GEP-NETs, we focused on those that may have a significant impact, and for which several studies have been conducted with relevant conclusions (Fig. 3).

\section{Platelet-derived growth factor: a pivotal factor in the TME of GEP-NETs}

PDGF is an ubiquitous growth factor released by many cell types (including platelets) whose expression has been observed in about 70\% of human GEP-NETs (Chaudhry et al. 1992, 1993). It binds two types of receptor tyrosine kinases (RTK), PDGFR- $\alpha$ and PDGFR- $\beta$ (Fredriksson et al. 2004), the latter being expressed by a majority of SI-NETs and PNETs and even further in case of liver or lymph node metastasis as compared to corresponding primary tumor sites (Funa et al. 1990, Fjällskog et al. 2007). Within the tumoral niche, this expression can be either exclusively limited to stromal cells (especially endothelial cells and pericytes) or sometimes observed in both tumoral and stromal cells (Funa et al. 1990, Welin et al. 2006, Fjällskog et al. 2007). Moreover, a decreasing level of PDGFR- $\beta$ expression is noted from the tumor to its periphery such that the closer the stromal cells are from the tumor, the higher PDGFR- $\beta$ expression they display (Funa et al. 1990). Interestingly, this expression was closely correlated with the density of capillary blood vessels, in line with the proangiogenic activities of PDGF isoforms as previously described (Risau et al. 1992, Cao et al. 2002, Cao 2013).

The second type of PDGF receptor, PDGFR- $\alpha$, is also expressed in clusters of tumor cells and occasionally on adjacent stroma of human GEP-NETs (Chaudhry et al. 1993).

In summary, the PDGF/PDGFR system is widely expressed in GEP-NETs, with a higher expression level close to the tumor epicenter. These data suggest that PDGF likely acts locally in a paracrine and/or autocrine manner, an assumption which is supported by its rapid clearance from the plasma with an half-life of less than 2 min (Fredriksson et al. 2004). Whether PDGF expression enters and participates to the tumorigenesis process remains elusive since no correlation has been properly established yet between the tumoral status and its degree of differentiation on the one hand, and the local expression of PDGF/PDGFR on the other hand (Fjällskog et al. 2003).

\section{Transforming growth factors alpha, beta and epidermal growth factor}

TGF $\alpha$ is a growth factor characterized by its close analogy to EGF and therefore its capability to bind the EGF receptor (EGFR). A majority of NETs co-express TGF $\alpha$ and EGFR (Nilsson et al. 1995, Krishnamurthy \& Dayal 1997, Srivastava et al. 2001), a condition which is believed to confer growth advantage to tumor cells (Wong et al. 1989). In vitro, a significant amount of TGF $\alpha$ was detected in the medium of primary cultures of SI-NETs and its secretion dramatically decreased by the addition of octreotide to the cells (Nilsson et al. 1995). Noteworthy, the addition of TGF $\alpha$ to these primary cultures of SI-NETs resulted in tumor growth stimulation (Nilsson et al. 1995), which confers to the TGF $\alpha$, proliferative properties in human SI-NETs cells that can be counteracted via somatostatin receptors activation. At the receptor level, EGFR mRNA was almost exclusively detected in cases of gastrinomas and sparsely in other types of GEP-NETs (Wulbrand et al. 1998).

TGF $\beta 1$ is another cytokine, which binds TGF $\beta$ R- 1 and TGF $\beta$ R-2, and paradoxically serves as a growth inhibitor at the beginning of tumor development but later becomes a growth accelerator for transformed tumors (Blobe et al. 2000, Roberts \& Wakefield 2003). In human GEP-NETs, both the tumor and the surrounding mesenchyme display a strong expression of TGF $\beta$, whereas TGF $\beta$ R- 1 and -2 expression was exclusively observed on the tumoral cells (Chaudhry et al. 1994, Wulbrand et al. 1998, Wimmel et al. 2003). This peculiar pattern of expression suggests that a local TGF $\beta$ loop of activation initiates from the tumor and the stroma to serve the tumor compartment. Thus, in BON-1 and QGP-1 human PNET cell lines, the addition of TGF $\beta 1(10 \mathrm{ng} / \mathrm{mL})$ resulted in a significant and time-dependent inhibition of BON-1 proliferation while no effect was observed in QGP-1 cells (Wimmel et al. 2003, Leu et al. 2008). The mechanism underlying the negative effect of TGF $\beta$ on $\mathrm{BON}-1$ proliferation may involve an upregulation of both the expression of p21 waf1/cip1 (a cyclin-dependent kinase inhibitor) (Pickup et al. 2013) and the secretion of somatostatin by 


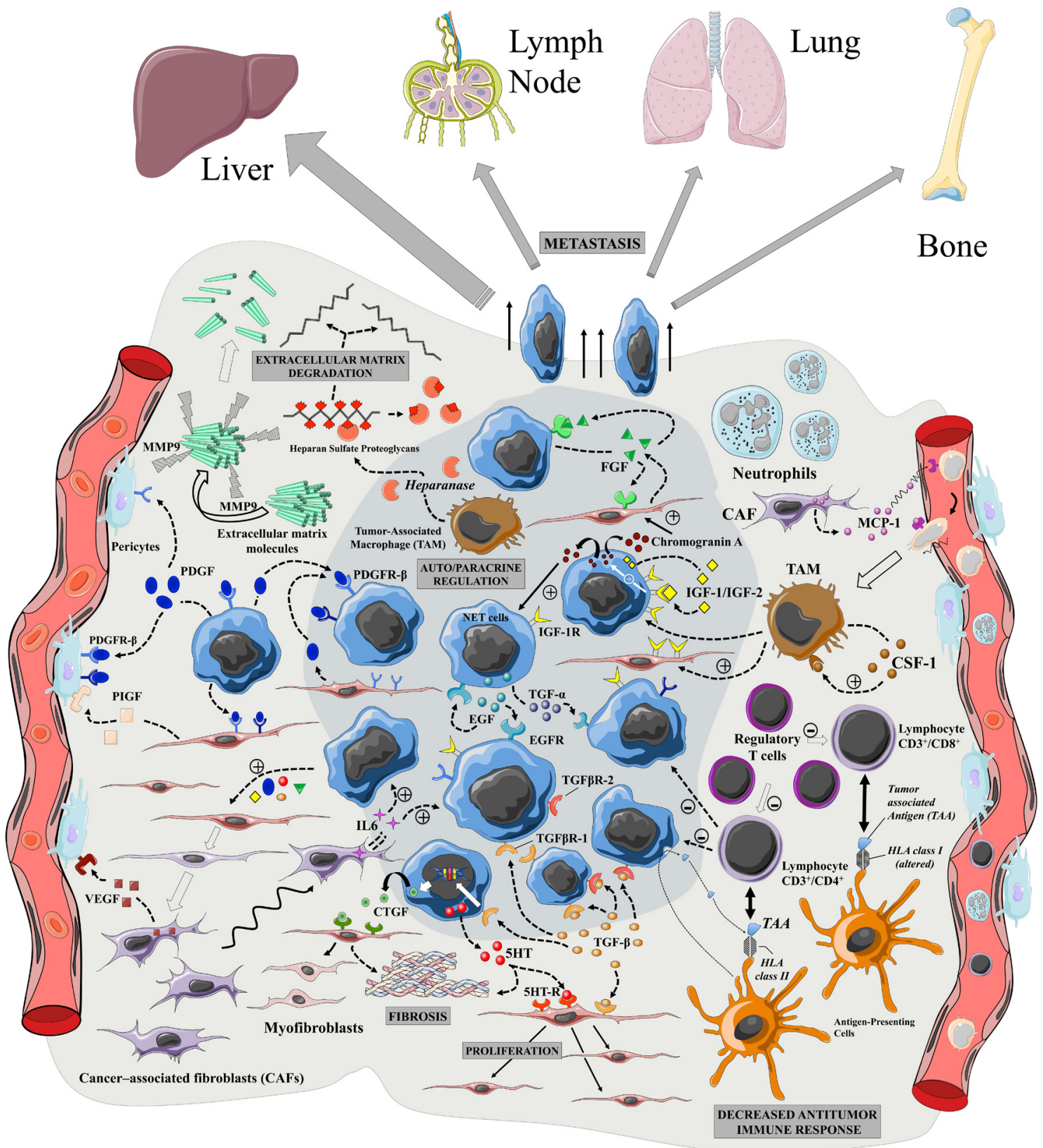

Figure 3

Schematic overview of the tumor microenvironment in digestive neuroendocrine tumors. Putative role and functions of the different components of the tumoral microenvironment, as described in this review.

BON-1 cells, a negative regulator of proliferation (Leu et al. 2008). On the other hand, TGF $\beta 1$ demonstrated proliferative action and an enhancement of the migration capability in the KRJ-I cells, a human-derived SI-NET cell line, due to loss of E-cadherin expression (Kidd et al. 2007a).

Summarizing, a limited number of studies has focused on the role of the TGF $\beta$ system in human GEP-NETs and the majority of these studies were observational, depicting whether this cytokine is expressed or not in the tumoral as well as in peritumoral tissues. The interest which is currently brought to the development of TGF $\beta$ inhibitors is based on the pleiotropic effect of this cytokine known to regulate, beyond its direct effect on tumor proliferation, immune cell function in normal and tumor-associated lymphocytes and tumor-associated fibrosis. As such, TGF $\beta$ inhibitors could represent an 'ideal' drug for treating simultaneously tumor and TME in GEP-NETs (Herbertz et al. 2015, de Gramont et al. 2017). 


\section{Placenta growth factor and the neuropilin system}

Placenta growth factor (PIGF) is a VEGF-homolog angiogenic growth factor, which supports pathological angiogenesis by binding to VEGFR-1 (also known as Flt1), neuropilin-1 (NRP-1) and -2 (NRP-2) (Parr et al. 2005, Wei et al. 2005, Fischer et al. 2008) Circulating plasma levels of PIGF are higher in patients with either PNETs or SI-NETs compared to controls (Hilfenhaus et al. 2013). In vitro, PIGF demonstrated capability to stimulate both proliferation and migration of BON-1, QGP-1 and KRJ-I. In human PNET samples, PIGF protein is almost exclusively detected within the TME (i.e. stromal cells such as endothelial and inflammatory cells) and occasionally in the tumoral compartment. In contrast, no staining is observed in both the normal endocrine and exocrine pancreatic tissues, suggesting that PIGF is de novo expressed during the process of tumorigenesis (Hilfenhaus et al. 2013).

Neuropilins, which bind PIGF, also act as co-receptors for the semaphorins, a class of proteins involved in the process of axon guidance during the nervous system maturation and in regulation of cell migration (Prud'homme \& Glinka 2012). More specifically, NRP-1 and NRP-2 are co-receptors for class-3 semaphorins (SEMA3), a potent angiogenesis inhibitor (Neufeld et al. 2005). A recent study showed that expression of semaphorin $3 \mathrm{~F}$ (SEMA3F) is almost indetectable in a series of human SI-NETs (primitive site and metastasis), while conserved in the normal neuroendocrine tissue (Bollard et al. 2015). The authors further showed that upregulation of SEMA3F in the enteroendocrine cell lines STC-1 and GluTag led to a reduced ability of the cell line to form tumors and liver metastasis in a xenograft model of SI-NET liver metastasis (Bollard et al. 2015).

\section{Connective tissue growth factor}

Connective tissue growth factor (CTGF/CCN2) is a 349 amino acid, which promotes fibroblast proliferation, migration, adhesion and extracellular matrix (ECM) formation (Moussad \& Brigstock 2000). The latter is illustrated by the development of fibrosis when CTGF is overproduced under the regulation of TGF $\beta$ (Grotendorst 1997). For instance, highest plasma concentrations and tumor expression of the full-length CTGF protein was observed in patients with NETs and clinically documentable fibrosis (Kidd et al. 2007b). Similarly, Bergestuen et al. reported an important elevation of plasma CTGF levels in patients with NETs and right unresectable dysfunction by valvular regurgitation, one known complication of serotonin-induced fibrosis (Bergestuen et al. 2010). At the tumoral level, CTGF is highly overexpressed in human SI-NETs compared to other types of NETs, with an especially pronounced immunoreactivity in the tumor cells adjacent to the surrounding fibrovascular stroma (Cunningham et al. 2010, Kaltsas et al. 2011). In vitro, CTGF demonstrated proliferative properties in KRJ-I, but had no effect on BON-1 (Siddique et al. 2009).

\section{Basic fibroblast growth factor}

Basic fibroblast growth factor (bFGF) belongs to a 22-member family of factors that bind to the fibroblast growth factor receptor (FGFR) and trigger carcinogenesis signaling pathways (Touat et al. 2015).

In human GEP-NETs, a strong immunostaining for bFGF was observed in the stromal component of tumor samples, especially in the macrophage subpopulation of cells (Chaudhry et al. 1993). The FGFR expression was also prominent in the stroma part of the tumor and almost undetectable in the tumoral cell compartment (Wulbrand et al. 1998). This particular pattern of expression could suppose that the FGF/FGFR system may be primarily active in an autocrine loop within the stroma to itself, rather than between the tumor and its stroma. Whether FGF acts as a promoter of fibrosis in the TME of GEP-NETs is unclarified yet. Comparable plasma levels of FGF2 expression were found in patients with SI-NETs as compared to their matched controls and, in patients with SI-NETs, whatever the existence of an extensive mesenteric sclerosis (Zhang et al. 2004, Pavel et al. 2005). To date, there are no phase III clinical trials with selective targeted agents against FGFR, which have been conducted and/or approved. A phase II clinical trial using Nindetanib, a small-molecule tyrosine kinase inhibitor targeting vascular endothelial growth factor receptor (VEGFR), fibroblast growth factor receptor (FGFR) and platelet-derived growth factor receptor (PDGFR), is currently ongoing in patients with well- or moderately differentiated, unresectable and/or metastatic, extrapancreatic NETs (ClinicalTrials. gov Identifier: NCT02399215).

\section{Insulin-like growth factors}

Several lines of evidence have been accumulated that both insulin-like growth factors, IGF-1 and IGF-2, and their receptor, IGF1R, are involved in the development and progression of cancer, including GEP-NETs in which a constitutive expression of IGFs and IGF receptors has been shown (Wulbrand et al. 2000, Kaltsas et al. 2011, van Adrichem et al. 2013). In gastrinomas, an increased expression of both IGF-1/IGF1R by the tumor was 
associated with a worse outcome in terms of curability and metastatic presentation (Furukawa et al. 2005).

In BON-1, experimental data showed that IGF-1 acts as an autocrine regulator of chromogranin A secretion and cellular growth (von Wichert et al. 2000, 2005, Mergler et al. 2005) and its effect could be reversed by the use of the IGF1R inhibitor, NVP-AEW541 (Höpfner et al. 2006). Our group recently showed that dopamine receptor subtype 2 agonists and the multiple somatostatin receptor analog, pasireotide, blocked the release of IGF-2 by BON-1 which suggests, in this model, an interaction between the IGF/IGF1R system and signaling pathways downstream dopamine and somatostatin receptors (van Adrichem et al. 2016). Monoclonal antibodies that target the IGF1/IGF1R system recently entered clinical trials in patients with GEP-NETs (see below).

\section{Chromogranin A: equivocal function in the TME of GEP-NETs}

Chromogranin A (CGA) and its fragments vasostatin-1 (VS-1) and -2 (VS-2) are specific markers of neuroendocrine cells that have previously demonstrated proliferative effects in NET cells (Giovinazzo et al. 2013). They could further influence the synthesis of TME components, as well as the vascularization dynamic phenomenon (Corti 2010). For instance, VS-1 exerts antiangiogenic (antiVEGF) effects in human umbilical vein endothelial cells and in mice models while CGA acts as a preventive factor of vascular leakage induced by tumor necrosis factor $\alpha$ (TNF $\alpha)$ (Ferrero et al. 2004). In addition, CGA seems to endorse inhibitory functions over fibroblast adhesion in the TME, as suggested in non-invasive breast carcinomas where the number of CGA-immunoreactive neuroendocrine cells was shown to be higher in comparison to invasive breast carcinomas (Kimura et al. 2002).

In experimental models of GEP-NETs, Giovinazzo et al. showed that (i) CGA mRNA and protein levels were both increased in SI-NETs compared to normal enterochromaffin cells, (ii) silencing of CGA, as well as prohormone convertase (which cleaves CGA to VS-1), decreased the proliferation of SI-NET cell lines (KRJ-I and STS cell lines) and eventually, (iii) SI-NET cell line (H-STS) proliferation was stimulated by VS-1 (Giovinazzo et al. 2013).

\section{The ECM of GEP-NETs: the structural support of} the TME

\section{Serotonin and fibrosis in the ECM of SI-NETs}

Fibrosis that occurs either local to or distant from the unresectable tumor is one of the hallmarks of
SI-NETs (Druce et al. 2009). Fibrosis is likely to occur in case of serotonin oversecretion (also known as 5 hydroxytryptophan (5-HT)), a biogenic amine whose synthesis depends on the tryptophan hydroxylase enzyme. When secreted in excess, patients can present with a plethora of vasoactive symptoms (e.g. diarrhea, flushing), together known under the name of carcinoid syndrome (Fig. 4). In vitro, serotonin demonstrated mitogenic properties in numerous cell types (Nemecek et al. 1986, Seuwen et al. 1988), including KRJ-I, in which it also triggers, by binding the $5-\mathrm{HT}_{2 \mathrm{~B}}$ serotonin receptor, the release of serotonin by the cells, in an autocrine manner. (Drozdov et al. 2009). In parallel, serotonin induced both proliferation and synthesis of profibrotic factors, namely CTGF, FGF2 and TGF $\beta 1$ in the HEK293 cell line, a cell line assumed by the authors of this study to be a fibroblast-like cell (Svejda et al. 2010). Unlike KRJ-I, in this cell type, the effect of serotonin was mediated by the $5-\mathrm{HT}_{2 \mathrm{~A} / \mathrm{C}}$ serotonin receptor. Subsequently, the authors demonstrated that, using a specific inhibitor of $5-\mathrm{HT}_{2 \mathrm{~B}}$ in a coculture experiment of KRJ-I and HEK-293 (where exchanges between the two cell types were permitted only through a semi-permeable membrane) an inhibition of both proliferation of HEK293 cells and synthesis of profibrotic factors by the cells occurred, underlying a molecular crosstalk between the two different cell types (Svejda et al. 2010). Such an experiment mimicks what is likely to happen in situ between the NET cells and the fibroblast component of the TME; however, to date, to the best of our knowledge, there are no studies on the functional role of serotonin in the TME of human GEP-NETs.

In summary, the understanding of the $5-\mathrm{HT} / 5-\mathrm{HT}$ receptor system in the field of SI-NETs is still based on results obtained in cell lines which, as previously mentioned, have limitations, and care should be taken to extrapolate these data to human NETs. Currently, research concerning serotonin in the setting of human GEP-NET mainly focuses on the control of high serotonin plasma levels rather than to elucidate its specific action within the TME. In this context, the new tryptophan hydroxylase inhibitor, telotristat ethyl, showed promising results in terms of control of carcinoid symptoms and reduction of serotonin metabolite, namely urinary 5-hydroxyindole acetic acid (u5-HIAA) particularly in patients with carcinoid syndrome refractory to usual somatostatin analogs (Kulke et al. 2014, 2017). The impact of this new agent on the fibrotic matrix surrounding the tumor remains unknown. 
A

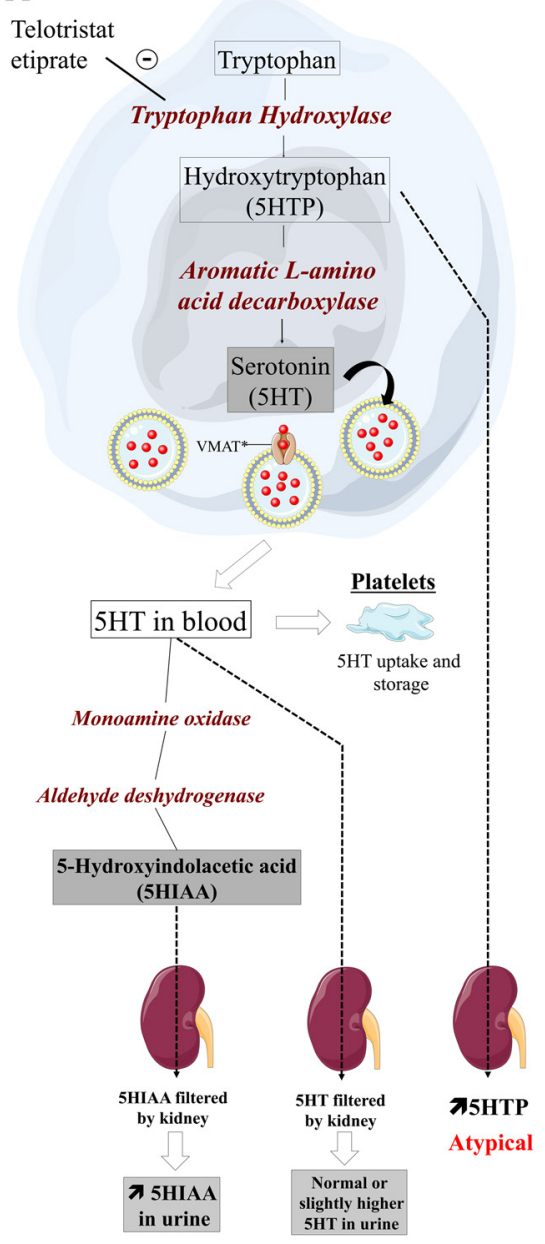

B

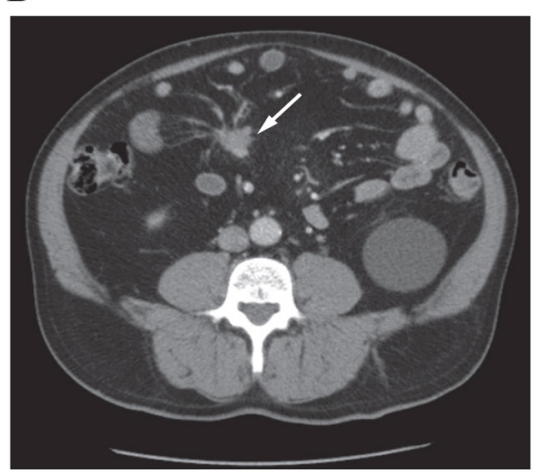

C

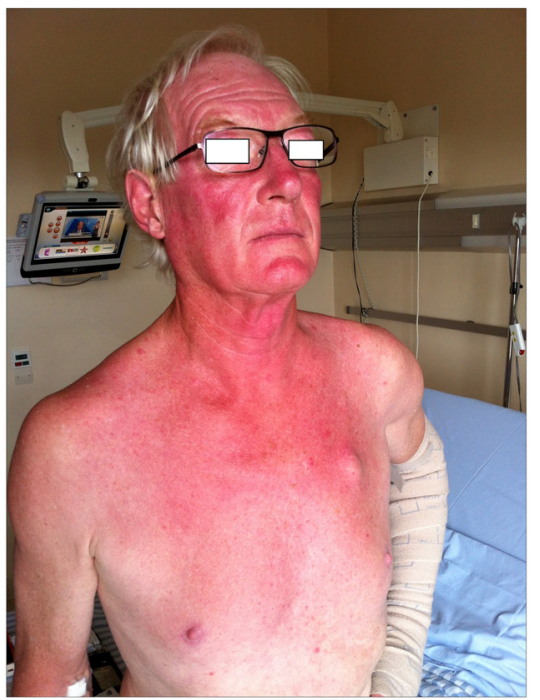

Figure 4

Carcinoid syndrome. (A) Biosynthesis of serotonin and renal excretion of 5HIAA. (B) Abdominal CT scan showing an ileal neuroendocrine tumor revealed by a fibrotic retractile mesenteritis (arrow). (C) Flushing occurring in a patient with carcinoid syndrome. *Vesicular monoamine transporter. Telotrist etiprate is a new tryptophan hydroxylase inhibitor. Written consent to publish was obtained from the patient.

\section{The remodeling of ECM in GEP-NETs: heparanases and matrix metalloproteinase enzymes represent potential therapeutic targets}

ECM remodeling is a critical process during multiple stages of tumor development and facilitates cancer cell proliferation, angiogenesis, invasion and ultimately metastasis. This process involves a plethora of factors among which the heparan sulfate proteoglycans (HSPGs) that consist of a protein core with covalently attached heparan sulfate (HS) side chains. In addition to provide structural integrity, HSPGs act as a storage depot for a variety of proteins that bind HS, including growth factors, angiogenic proteins and chemokines (Vlodavsky et al. 2012). In human GEP-NETs, a differential regulation of a subgroup of HSPGs (i.e. syndecan 2, glypican 1 and 5), which depends on the tumor differentiation and its grading was shown (García-Suárez et al. 2014). For instance, syndecan 2 acts as a cell surface receptor (or 'docking' receptor), able to interact with many extracellular molecules within the TME. Its downregulation in high-grade compared to low-grade NETs may be one of the reasons that explain a high capability of tumor spread and metastasis in high-grade cases (García-Suárez et al. 2014). Likewise, the chondroitin sulfate proteoglycans (CSPGs), which are also able to interact with molecular and protein partners within the TME, are highly expressed in the tumor stroma compared to the normal stroma, which suggests (i) a certain degree of induction during the tumorigenesis and (ii) that they might serve in this situation as docking proteins to promote local growth of the tumor by the release of various growth factors and/or cytokines (García-Suárez et al. 2014). The release of growth factor by the processing of HSPGs is performed exclusively by enzymes called heparanase whose activity can therefore lead to both physical remodeling of the ECM and the conversion of tethered growth factors to soluble bioactive mediators once released (Vlodavsky et al. 2007). Heparanase is upregulated during multistage tumorigenesis in the RipTag2 mice (Joyce et al. 2005) and more recently, a significant correlation between high 
heparanase expression/staining and a more advanced tumor stage, a higher tumor grade and the presence of distant metastasis in patients with PNETs was reported (Hunter et al. 2014). In RipTag2 mice, the overexpression of heparanase by tumor-associated macrophages (TAMs) is associated with a higher incidence of invasive tumors (micro- and macro-invasive), compared to either the WT mice or the heparanase knock-out RipTag2 mice (Hunter et al. 2014). Interestingly, the latter model was further marked by an increase in angiogenesis, pericyte coverage and a wider vascular network, which is more generally associated with low-grade tumors in human GEP-NETs as discussed earlier.

Matrix metalloproteinases (MMPs) are proteinases that also contribute both to the degradation, as well as the modeling of the ECM (Kessenbrock et al. 2010). Additionally, in the RipTag2 mice, MMPs, especially MMP9, seem to be a critical factor that promotes the angiogenic switch of the PNET carcinogenesis (Shchors et al. 2013). When absent or deleted, MMP9-deficient mice exhibited more aggressive/invasive PNETs, suggesting, once again, that angiogenesis is a feature of 'low-grade' NET and blocking angiogenesis may promote in the end the emergence of more invasive tumors, presumably by reactivating other signaling pathways such as the ones involved in hypoxia metabolism.

\section{The cellular actors of the TME: immune cells and fibroblasts}

Immune cells The immune response to tumors has been extensively described and analyzed for many years and forms the basis for the development of immunotherapy (Blattman \& Greenberg 2004).

In human GEP-NETs, several tumor-associated antigens (TAA), which are cancer-specific surface molecules generally overexpressed and recognized by the immune system, have been identified, like for instance chromogranin A- or VMAT1 (vesicular monoamine transporter 1)-derived TAA (Wuttke et al. 2009). In addition, NETs were shown to have an infiltration of lymphocytes CD3+/CD4+, CD3+/CD8+immunopositive cells (Vikman et al. 2009, Katz et al. 2010). In SI-NETs, this infiltrate was accompanied by an important infiltration of $\mathrm{T}$ regulator lymphocytes (Tregs) that fight against recruitment of anti-tumor effector $\mathrm{T}$ cells within the tumor niche with a more important infiltrate observed in metastasis as compared to the primitive tumor site (Katz et al. 2010). Whether this $\mathrm{T}$ cell infiltrate is 'immunologically' efficient remains difficult to establish. In addition to an infiltration of Treg lymphocytes, a loss of expression of HLA class I components (e.g. the $\beta 2$-microglobuline), necessary for epitope presentation to CTLs, was identified in 10/11 PNET samples, suggesting that despite the presence of both TAA and CTLs, the tumorspecific immune response can be hampered through a different mechanism (Ryschich et al. 2003).

Besides a direct modulation of the cytotoxic response, others aspects potentially contributing to a non-proper immune response within the tumor niche have been described such as a reduction of systemic Th- 1 promoting cytokines, like IL-1 $\beta$ (Vikman et al. 2009) or the local release of soluble factors by the tumor cells that can completely block the maturation and function of dendritic cells (Katsenelson et al. 2001).

Besides the lymphocyte population, the role of TAMs in tumor initiation and progression is complex, with variable pro- and anti-tumor-promoting effects in different types of cancers (Lewis \& Pollard 2006). In Rip-Tag2 mice, a decrease in TAMs infiltrates is associated with less PNETs foci (Pyonteck et al. 2012). In 27 human PNETs tissue sample, a higher infiltration of TAM, assessed by CD68 immunostaining, correlated with a higher tumor grade and stage and more frequent liver metastases (Pyonteck et al. 2012). Mast cells also raised interest in the field of tumor-associated immune cells. Their importance in the tumor expansion of islet cell tumors is underlined by Soucek et al. who showed that the recruitment of mast cells was required for tumor expansion and, reciprocally, that inhibition of mast cell function led to hypoxia and both tumor and endothelial cell death (Soucek et al. 2007, Theoharides 2008). Of interest, the same group showed that treatment of insulinoma-bearing mice with a novel inhibitor of Bruton tyrosine kinase (Btk) that blocks mast cell degranulation (PCI-32765), resulted in tumor vasculature collapse and tumor regression (Soucek et al. 2011).

Over the past few years, the program death 1 (PD-1) and its ligands PD-L1/PD-L2 pathway progressively became one of the most interesting immune check points for the development of immune therapies in solid tumors, including GEP-NETs (Chen \& Han 2015). The PD-1 pathway is a negative immune checkpoint that anergizes the Th1 cytotoxic immune response and, therefore, counteracts the cytotoxic action of $\mathrm{T}$ lymphocytes against tumoral cells (Fig. 5). Its upregulation is one key immunosuppressive mechanism by which cancer avoids its eradication by the immune system. Blockade of this pathway with antibodies to PD-1 or its ligands (pembrozilumab, nivolumab, atezolizumab) has led to remarkable clinical responses in patients with many 
A Innate immune resistance

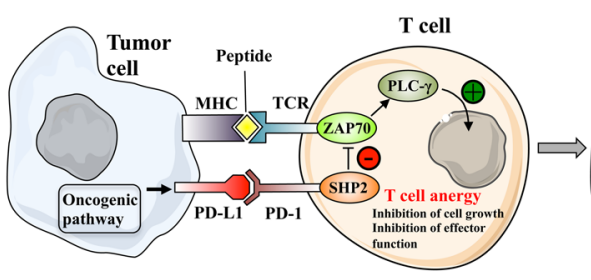

B Anti-PD-L1 therapy

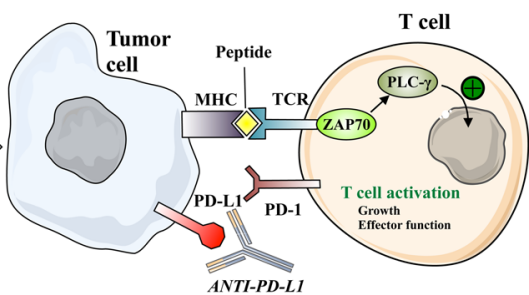

C Acquired immune resistance
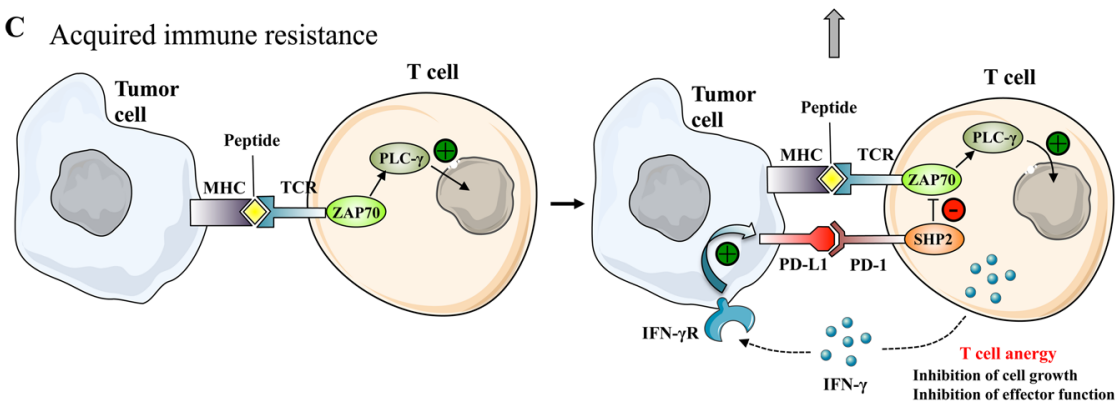

\section{Figure 5}

Schematic representation of the PD-1/PD-L1 system in the setting of innate (A) or acquired (C) immune resistance and the effect of the immune checkpoint inhibitor anti-PD-L1 (B). MHC, major histocompatibility complex; TCR, T-cell receptor. different types of cancer (Ferris et al. 2016, Reck et al. 2016, Bellmunt et al. 2017). In human GEP-NETs, the expression of PD-L1 was observed only in a subset of patients (22\%), irrespective of the primary tumor site (Kim et al. 2016). However, its expression was significantly higher in grade 3 tumors according to the 2010 WHO classification. Interestingly, a significant expression of PD-L2 (the second ligand for PD-1) was observed in both PNET and SI-NET (da Silva et al. Poster B3, NANETS 2016). These encouraging data could pave the way for the use of current immune checkpoint inhibitors in GEP-NETs (Ghiotto et al. 2010). There are currently several clinical trials testing the PD-1 antibody pembrolizumab (ClinicalTrials.gov Identifier: NCT02939651, NCT03290079, NCT03290079, NCT03012620, NCT03043664) and nivolumab (ClinicalTrials.gov Identifier: NCT03420521) in different stages of GEP-NETs (mostly high-grade tumors).

Fibroblasts Fibroblasts are an integrated component of the TME and emerge progressively as a cornerstone actor of the stroma by ensuring the production of growth factors, chemokines, ECM and by facilitating the angiogenic recruitment of endothelial cells and pericytes. Via a modification of their phenotype, the 'activated' fibroblasts, referred to as cancer-associated fibroblasts (CAFs), play an important role in the malignant progression of the cancer and represent an important target for cancer therapies (see review: Kalluri $\&$ Zeisberg 2006). While the implication of CAF in the TME of ductal pancreatic cancer has been extensively studied and described (Feig et al. 2012), much less is known about their role in the field of GEP-NETs.
In the early 90s, Beauchamp et al. observed that conditioned medium of the BON-1 cell line stimulates DNA synthesis and the fibroblast colony growth (Beauchamp et al. 1991). In this study, the BON-induced proliferation of fibroblasts was related to the release of TGF $\beta$, a cytokine known to considerably influence the functionality of the fibroblast within the TME in a multimodal way (Pickup et al. 2013). We similarly identified through conditioned medium experiments that both BON-1 and QGP-1 were able to stimulate the proliferation of human fibroblast cell lines and vice versa (personal unpublished data). Through a proteomic approach, Bowden et al. screened in vitro a panel of 55 proteins with known carcinogenic associations and potentially secreted by CAFs in NETs. Five out of 55 proteins were identified as being significantly up or downregulated, compared to the supernatant of cultured normal human fibroblasts, including an elevated secretion of IL-6, MCP-1 and VEGF and suppressed levels of IL-8 and bFGF (Bowden et al. 2014). Of note, both fibroblast-mediated secretion of IL- 6 and VEGF were reported to be notably increased under TGF $\beta$ actions in the neuroendocrine TME (Pickup et al. 2013).

In summary, several lines of evidence strongly support the existence of interactions within the TME of GEP-NETs. In the past years, studies have focused in particular on the study of growth factors and their respective receptors, because they were known to be involved in the pathogenesis of other tumor models. These multiple and diverse targets within the TME currently constitute the rationale for the use of pharmacological targeted therapies and the rationale for the development of future pharmacological agents. 


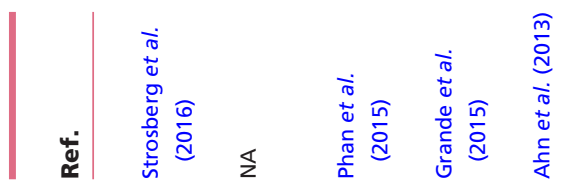

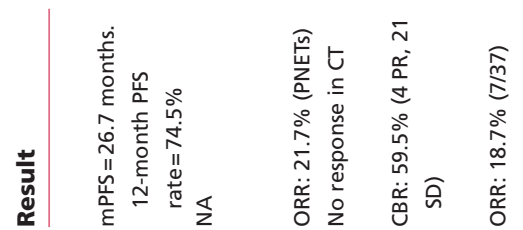

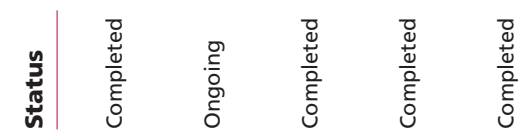

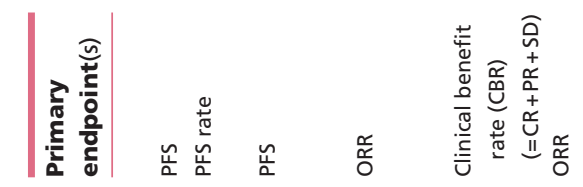

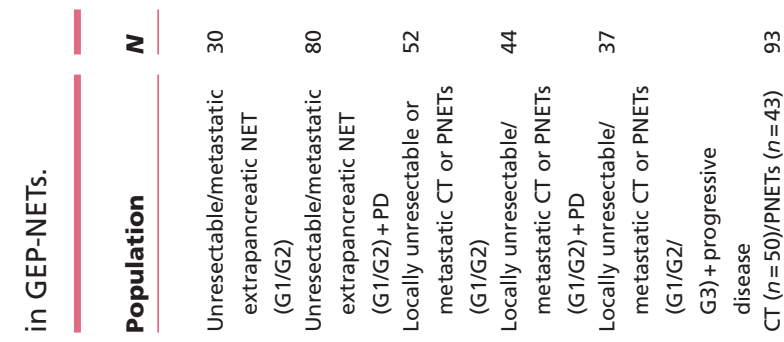

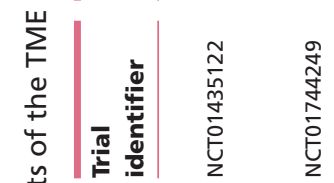

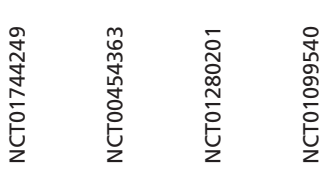

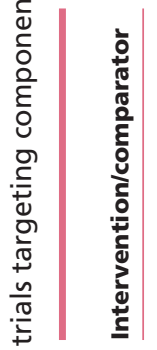

$\stackrel{2}{2}$

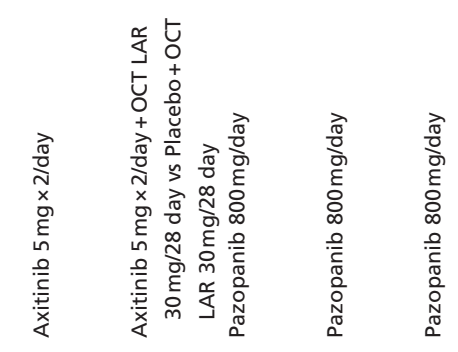

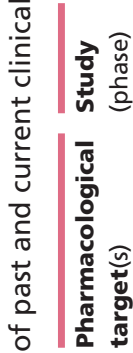

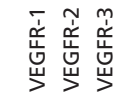
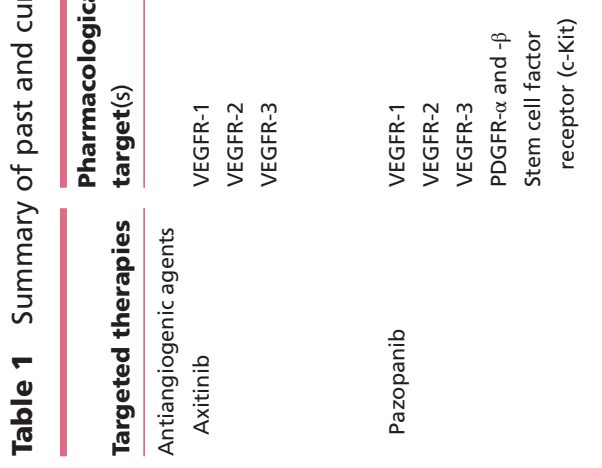

m

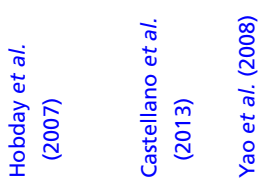

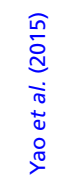

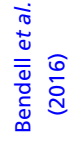

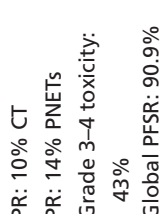

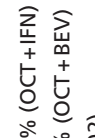

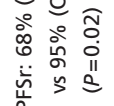

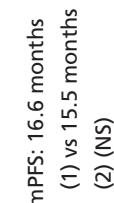

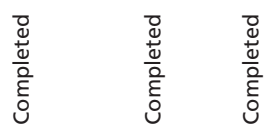

웜

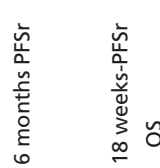

产

\& $\quad$

남

兹

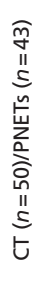

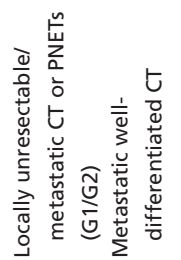

ơ

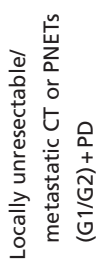

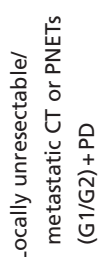

http://erc.endocrinology-journals.org https://doi.org/10.1530/ERC-18-0025 $\frac{\bar{\sigma}}{\frac{\bar{m}}{\bar{m}}}$
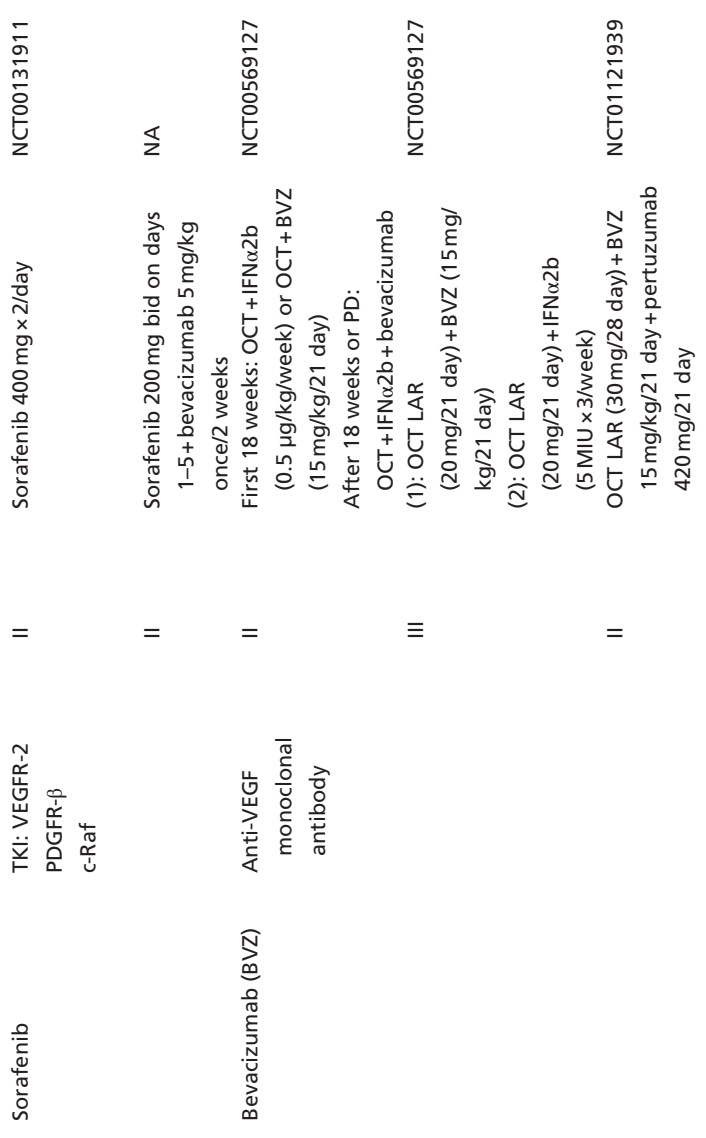


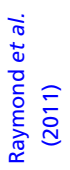

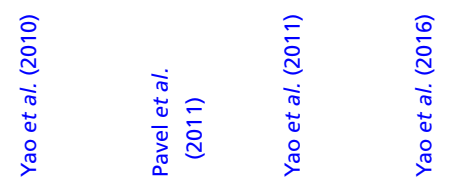

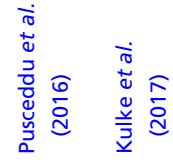

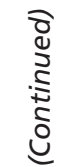

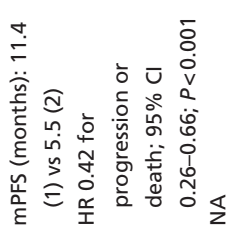

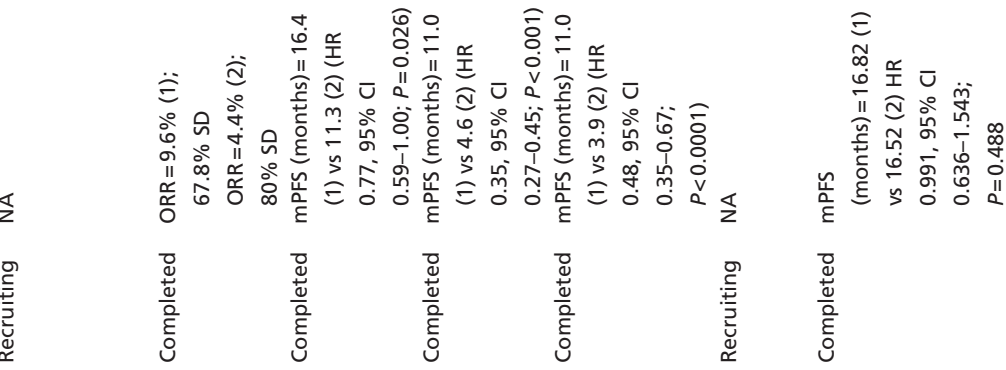

$\mathbb{s} \quad \mathbb{s}$

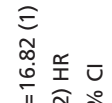

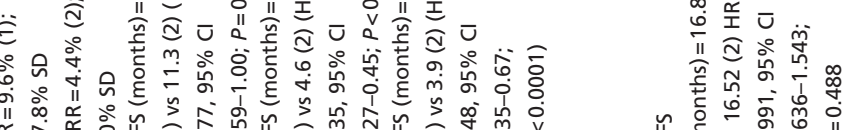

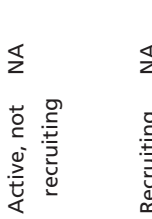

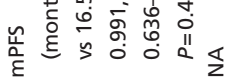

$\mathbb{s}$

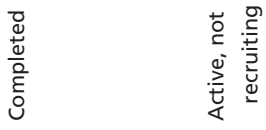

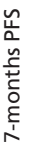

똥

$\Sigma$

옹

产

뜬 뜬

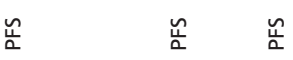

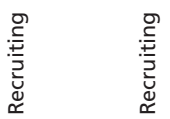

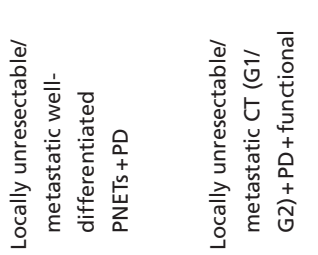

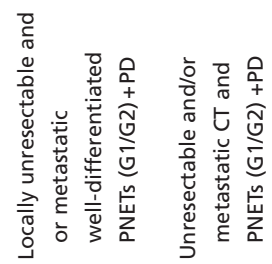

ริ

\% \&

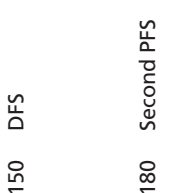

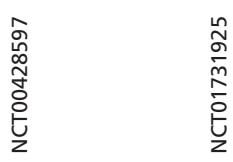

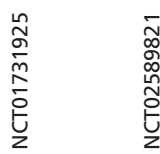

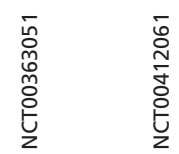

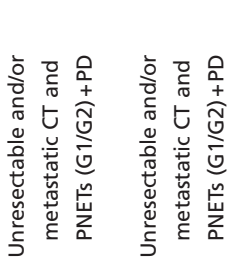

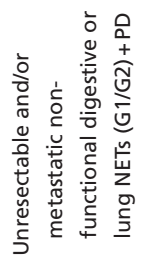

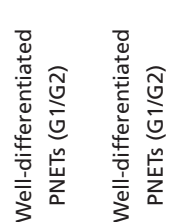

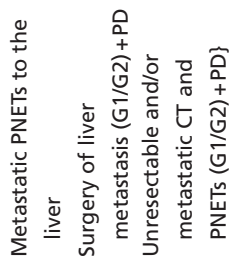

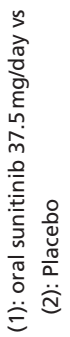

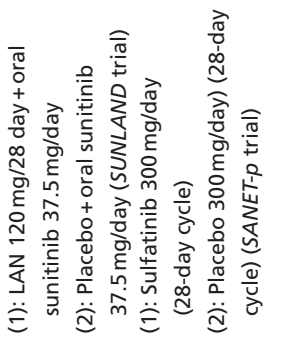

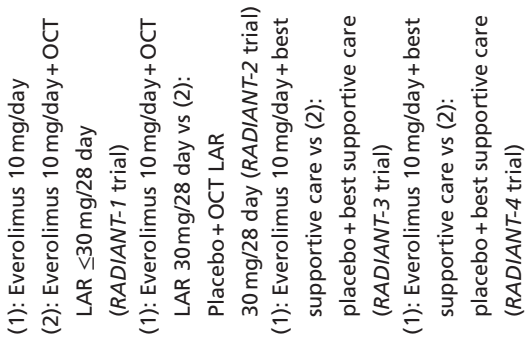

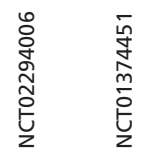

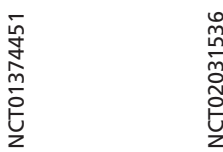

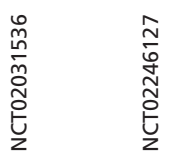

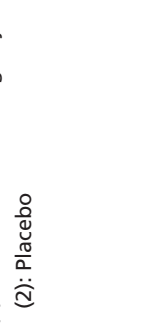

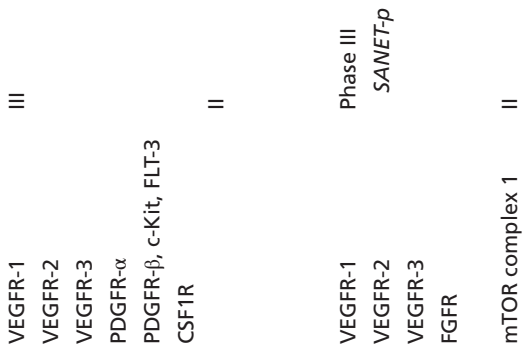
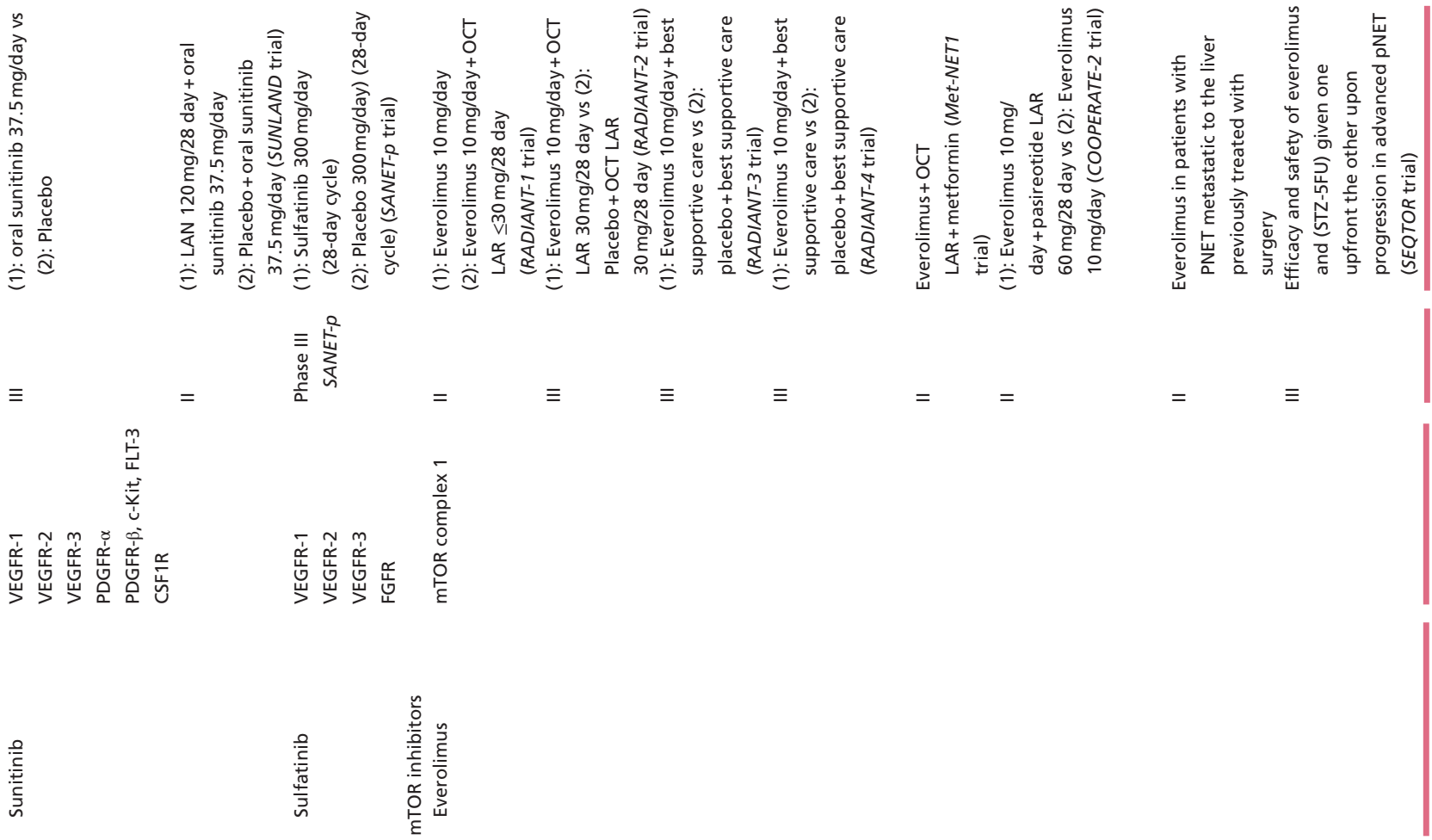


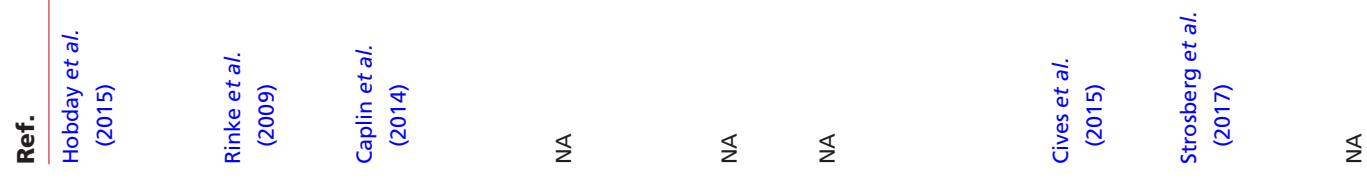

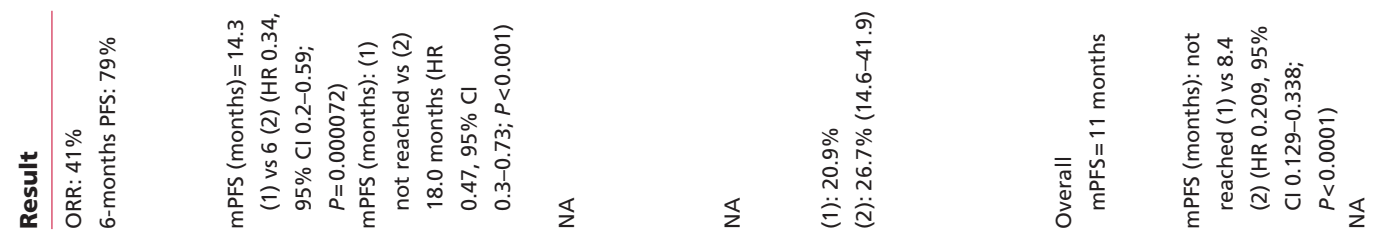

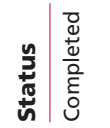

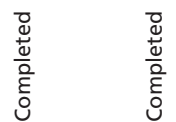

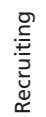

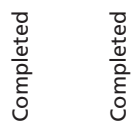

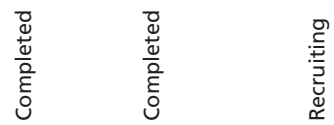

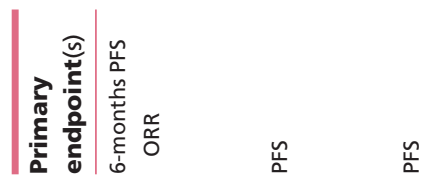

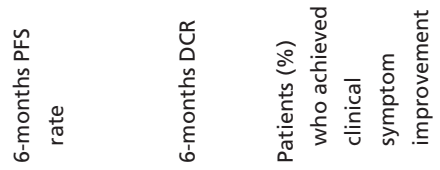

| $2 \mid \infty$ 冓 离 N

กิ ก $\stackrel{\infty}{\infty}$

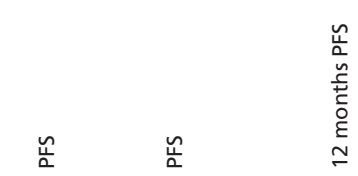

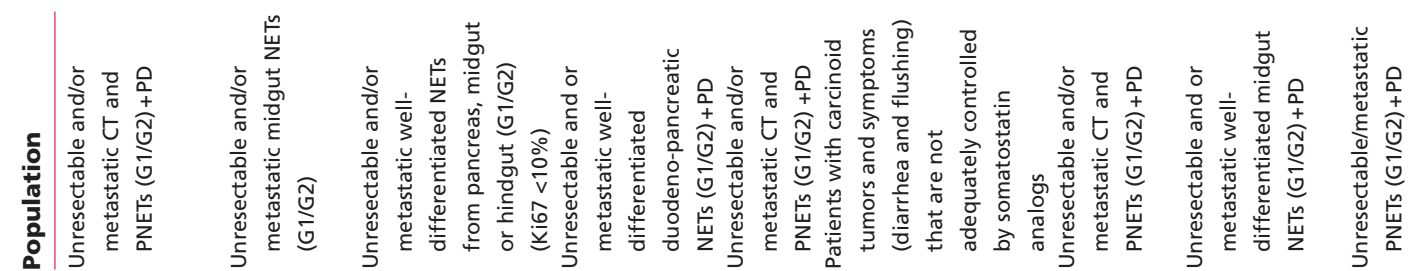

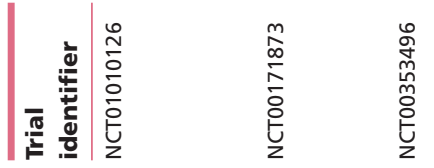

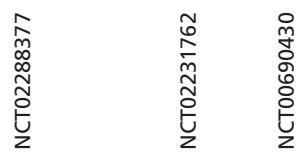

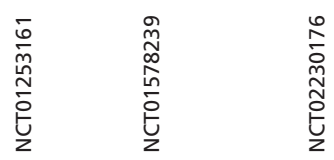
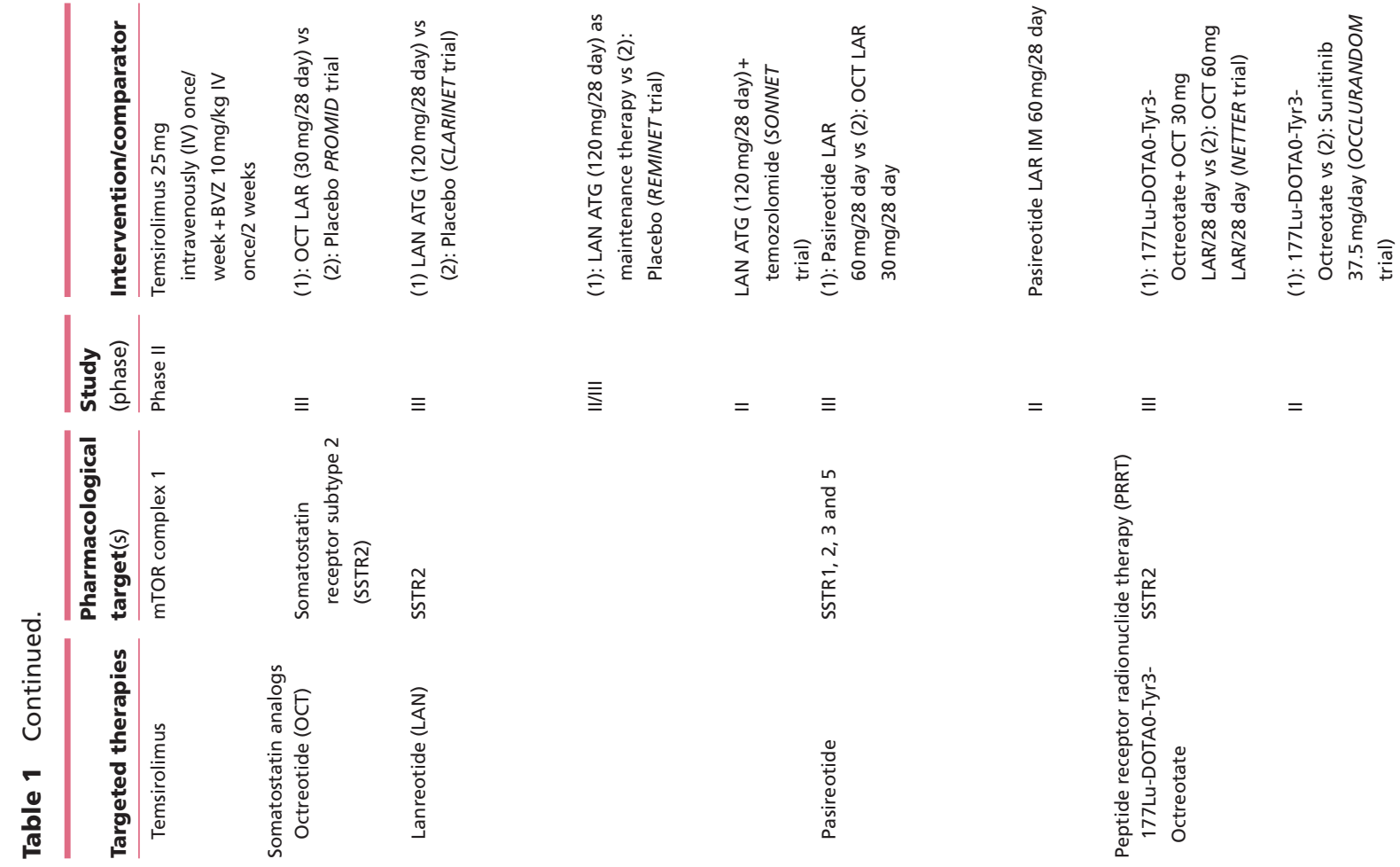

http://erc.endocrinology-journals.org https://doi.org/10.1530/ERC-18-0025

(C) 2018 Society for Endocrinology Printed in Great Britain
Pristed by Bioscientifica Ltd. 


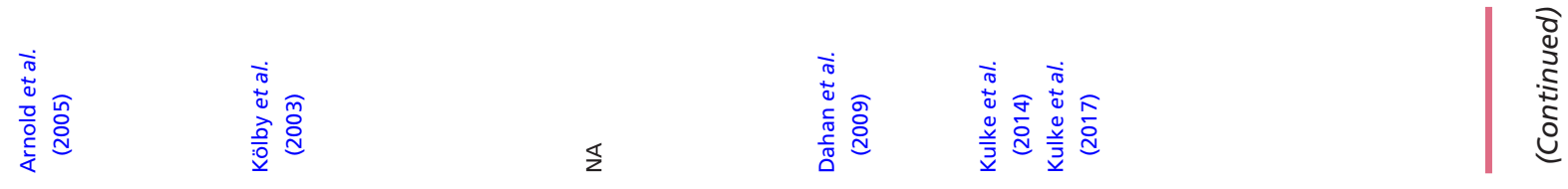

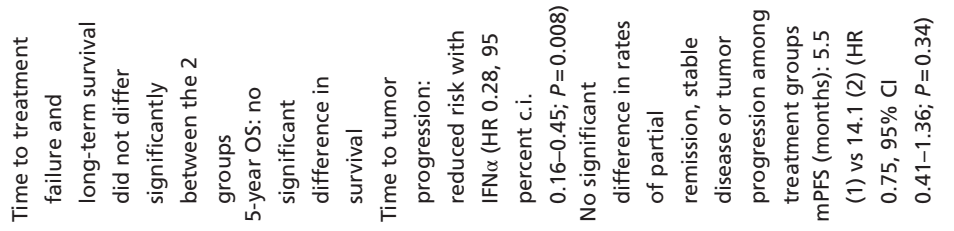

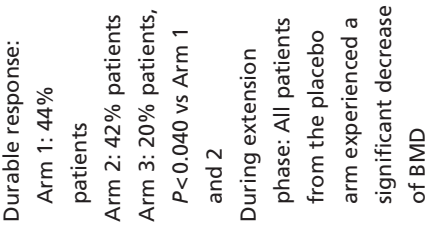

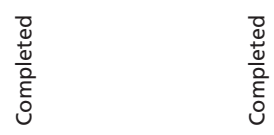

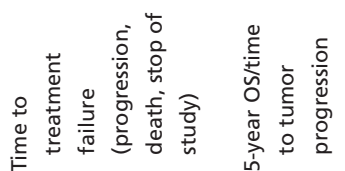

$\stackrel{9}{\circ}$

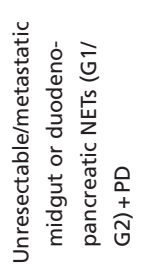

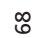

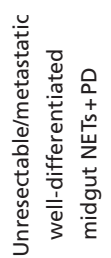

$\frac{\infty}{2}$

$\frac{\infty}{z}$

商

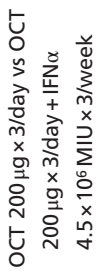

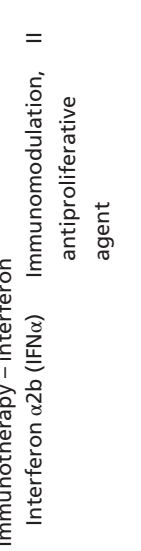

惫

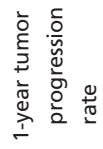

$\infty$

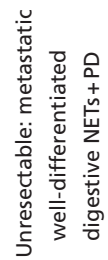

$\frac{\infty}{2}$

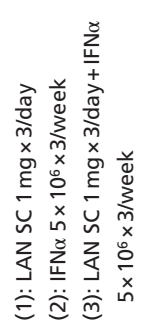

$\stackrel{s}{z}$
宽

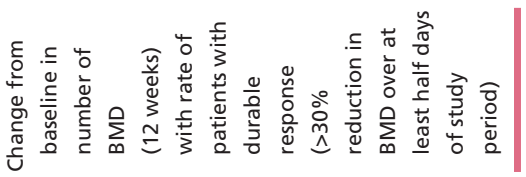

I. $\stackrel{\stackrel{m}{m}}{\square}$

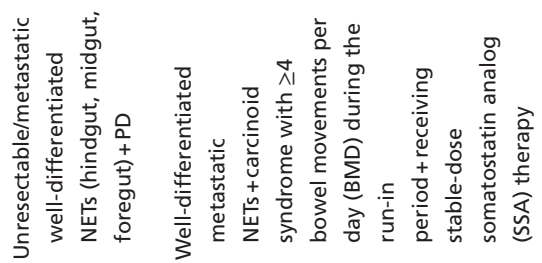

$\circ$
$\frac{0}{2}$
$\frac{1}{0}$
$\frac{0}{2}$
$\frac{2}{2}$

这
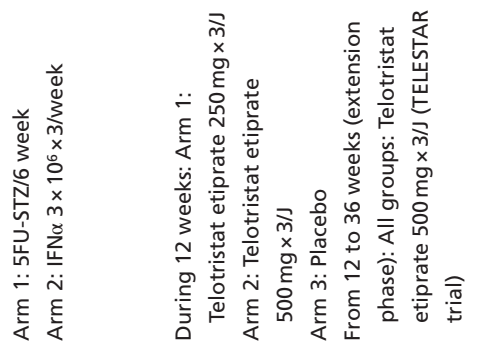

$\equiv$
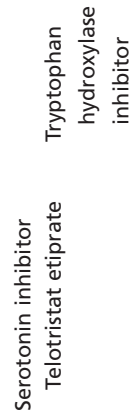

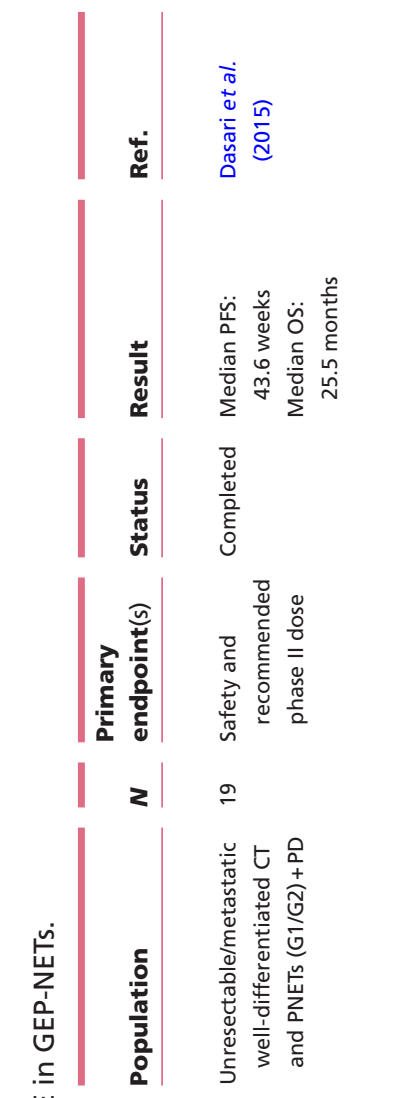

$\$ \quad \frac{a}{2}$

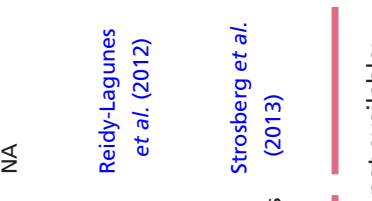

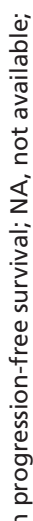

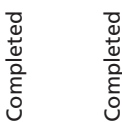

$\frac{\text { क्ष }}{\frac{+}{0}}$

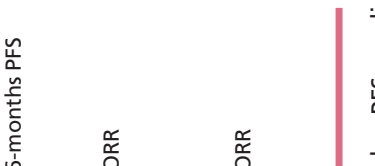

$$
\text { s }
$$

\section{Therapeutic targets in the TME of GEP-NETs: clinical trials and future perspectives}

\section{Angiogenesis and mTOR pathway inhibitors}

In clinical trials, small molecules have been developed to target VEGF signaling, such as tyrosine kinase inhibitors (TKIs) directed toward many receptors, including VEGF-Rs, humanized anti-VEGF antibody (bevacizumab, aflibercept) and inhibitors of the mTOR signaling pathway (mTORi) (Cao 2014) (Table 1). Sunitinib malate, a TKI directed against PDGF-R ( $\alpha$ and $\beta$ ), VEGF-R ( 2 and 3 ) and c-kit (stem cell factor receptor), showed both antitumor and antiangiogenic effects in RipTag2 mice (Pietras \& Hanahan 2005). Clinically, the drug significantly improved progression-free survival (PFS) and the objective response rate as compared with placebo among patients with advanced PNETs (Raymond et al. 2011). As discussed earlier, blocking the VEGF-R axis in preclinical models of GEP-NETs gives rise to hypoxia, which is one of the mechanisms of acquired resistance to antiangiogenic therapies. Based on results from animal models, another approach could be to simultaneously block VEGF and other factors released in the TME of GEP-NETs such that it has been showed for FGF blockade (Casanovas et al. 2005, Allen et al. 2011) or the cMET receptor (Sennino et al. 2012, 2013). The hepatocyte growth factor (HGF), the ligand of cMET, has been recently identified as a critical promoter of a resistance to treatment state toward melanoma human cell lines treated with BRAF inhibitors (Straussman et al. 2012). Although the cMET receptor is expressed in human samples of PNETs (Fig. 6), its functional role in the TME of GEP-NETs requires further investigations.

Besides specific antiangiogenic drugs, SSAs previously demonstrated antiangiogenic properties as well (Albini et al. 1999). Inhibition of angiogenesis through repression of endothelial cells proliferation is mediated either via the somatostatin receptor subtype 1 (SSTR1) (Bocci et al. 2007, Walter et al. 2011) or SSTR3 (Florio et al. 2003, Adams et al. 2004). On the other hand, in an in vivo experimental animal model of intrahepatic dissemination of the somatostatin-producing endocrine cell line STC-1, no effect of octreotide on tumor growth and intratumoral microvascular density was observed, suggesting a potential adaptive mechanism by the microenvironment (Walter et al. 2011). In human GEP-NETs, there are no studies that focused on a measurable antiangiogenic impact of SSAa, independent from a direct anti-tumor effect.

The Pi3K/AKT/mTOR has also been a target of interest in the treatment of GEP-NETs, especially since the mTOR 
pathway was shown to be dysregulated in a subset of PNET (Jiao et al. 2011) and because the PI3K/AKT/mTOR pathway is connected to angiogenesis through HIF (hypoxia inducible factor)-dependent and -independent mechanisms (Karar \& Maity 2011). Accordingly, in animal models of either gastric or colorectal cancer, the mTOR inhibitor everolimus significantly decreased microvessel density, suggestive of a direct effect on the TME (Onoyama et al. 2013, Yuge et al. 2015). Major clinical trials have been published over the past few years with the use of mTOR inhibitor everolimus in the field of NETs with significant impact over the PFS of treated patients vs the placebo group (Yao et al. 2011, 2016, Pusceddu et al. 2016).

\section{IGF-1/IGF-1R blockade}

In the field of GEP-NETs, a pilot study investigated the effect of NVP-AEW541, an IGF1R tyrosine kinase inhibitor able to block the activation of both PI3K/Akt/ mTOR and RAF/MEK/ERK pathways, in BON-1 and in an insulinoma cell line. NVP-AEW541 dose-dependently inhibited the proliferation of NET cells by inducing both apoptosis (assessed by the caspase 3 activity) and cell cycle arrest. Moreover, its anti-neoplastic effect was also detected in primary cultures of human neuroendocrine gastrointestinal tumors (Höpfner et al. 2006).

Subsequently, phase-I/II studies have been conducted with monoclonal antibodies directed against the IGF-1R in patients with well-differentiated GEP-NETs, however, without significant results in term of objective response rate (Table 1). The resistance to IGF-1R inhibitor in vivo, despite convincing results observed in vitro, may be, at least partially, explained, once again by an adaptative mechanism elicited by the TME, as suggested by Lee et al. where they showed in a murine model of orthotopic breast tumor that treatment with IGF-1R antibody paradoxically accelerates tumor infiltration of stromal cells and metastatic tumor growth through a STAT3dependent transcriptional upregulation of IGF-2 by the cancer cells (Lee et al. 2015).

In summary, the IGF/IGF-1R system is highly complex and includes, besides the classical IGF-1/IGF-1R couple, the insulin receptors that can also be activated by IGF-1 and many binding proteins called the IGFBPs. As a consequence, it seems unlikely that monotherapies using antibodies specifically directed toward the IGF-1R will be successful, but IGF-1/IGF-1R targeting may still be of interest for a co-targeting therapeutic strategy.

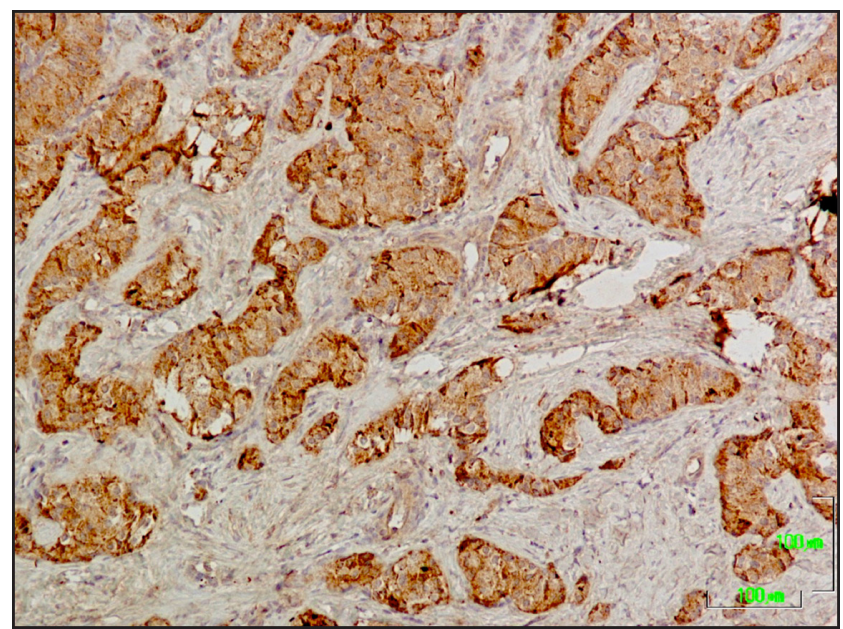

Figure 6

CMET expression by IHC in a well-differentiated grade 2 human pancreatic neuroendocrine tumor (original magnification $\times 100$ ). The section was stained with antibody against human CMET (8F11, Leica Biosystems, Newcastle, UK, at 1:60 dilution). Unpublished personal data.

\section{Inhibition of the serotonin pathway}

Since 2007, telotristat etiprate has emerged as a new therapeutic option for patients with GEP-NETs and refractory carcinoid syndrome (Kulke et al. 2014). Telotristat etiprate is an oral, systemically available, smallmolecule inhibitor of peripheral serotonin synthesis by inhibition of the tryptophan hydroxylase, the rate-limiting enzyme in the conversion of tryptophan to serotonin. In a prospective randomized study, patients with evidence of carcinoid tumor and $\geq 4$ bowel movements (BMs)/day, despite stable-dose octreotide LAR depot therapy, were enrolled in sequential escalating cohort and assigned to either placebo or telotristat etiprate at 150, 250, 350 or $500 \mathrm{mg}$ three times a day (Kulke et al. 2014). Among evaluable telotristat etiprate-treated patients, 5/18 (28\%) experienced $\mathrm{a} \geq 30 \%$ reduction in $\mathrm{BM}$ frequency for $\geq 2$ weeks, 9/16 (56\%) experienced biochemical response ( $\geq 50 \%$ reduction or normalization in u5-HIAA) at week 2 or 4 and 10/18 (56\%) reported adequate relief during at least 1 of the first 4 weeks of treatment. Similar activity was not observed in placebo-treated patients. In a multicenter trial in 14 patients with metastatic well-differentiated neuroendocrine tumors ( $66 \%$ from the midgut) responsible for a carcinoid syndrome, telotristat etiprate resulted in both a reduction of BM/day in every patient (with a mean decrease of $43.5 \%$ ) and a $73 \%$ decrease of the mean u5-HIAA concentration after 12 weeks of treatment (Pavel et al. 2015). Finally, the clinical utility of telotristat for reduction of BM frequency and u5-HIAA in patients with carcinoid syndrome not adequately controlled by SSAs 
was recently reported in a phase III clinical study (Kulke et al. 2017) (Table 1). The potential impact of this drug over the TME of GEP-NETs remains currently unknown.

\section{Interferon therapy}

Because of its antiangiogenic, as well as its immunomodulatory properties (Tompkins 1999, von Marschall et al. 2003), interferon alpha (IFN $\alpha$ ) has also been proposed in the management of NET. However, IFN $\alpha$ use has been limited due to toxicity and perceived limited efficacy (Mirvis et al. 2014). In vitro studies conducted in BON-1 provided several lines of evidence that IFN- $\beta$ was an even more potent inhibitor of proliferation compared to IFNa (Vitale et al. 2006). IFNs exert their effect via the type I IFN receptor (IFNAR-1, IFNAR-2c), but the level of IFNAR expression in GEP-NETs is currently unknown. Several clinical trials using IFNa as monotherapy or in combination have been published in the field of GEP-NETs (see review: Alonso-Gordoa et al. 2014 for details) and its efficacy, even partial, suggests intricate mechanisms that remain poorly understood to date. One of the effects could be the induction of class I antigens ( $\beta 2$-microglobuline) on tumor cells deficient in such expression, as previously shown in SI-NETs (Funa et al. 1986). A similar effect of IFN $\alpha$ on the TME of GEP-NETs was suggested by observation of an antineovascular activity in BON-1 xenografted mice model (Liu et al. 2006). Finally, a direct effect of IFN $\alpha$ on the tumoral cell itself by induction of apoptosis and modulation of cell cycle proteins were reported in several experiments (Detjen et al. 2000, 2002, Zhou et al. 2002).

In summary, the development of the current targeted therapies now available in GEP-NETs marked a little revolution as they were able, by definition, to specifically block a molecular target known to regulate the tumor development and behavior. As such, they were supposed to preserve the patients from the adverse effects usually encountered with intravenous systemic chemotherapies. Based on the clinical experience, it henceforth appears that the influence of the TME over the tumor growth and its capability to escape from the treatment has to be increasingly taken into consideration and two intended goals are currently assumed in that sense: first, to control (and ideally reduce) the primitive tumor growth, and second, to decrease the capability the tumor cells have to metastasize. Sunitinib malate, mTORi and SSA LAR have achieved clinical impact in phase III clinical trials. However, their efficiency is now challenged by the occurrence of resistance to treatment state the tumor can adopt. There could be a rationale to target, alternatively to VEGF, multiple growth factors or their receptors known to promote carcinogenesis such as PDGF, IGF or PIGF, but experimental data focusing on those factors are mostly observational and/or conducted in animal models. Furthermore, one could assume that whatever the number of growth factor pathways blocked, the tumor cells will indefinitely reactivate alternative signaling pathways (including under the influence of their TME) and eventually overcome the treatment efficacy at one point. An innovative approach could be to simultaneously target the tumoral cells and pivotal components of the TME, for example, the combination of antiangiogenic drugs with the cytotoxic action of immune checkpoint inhibitors, which have shown promising results in other models of tumors.

Less is known about the impact of the current treatment over the capability the tumor cells have to metastasize, and a number of innovative targets deserve attention. As discussed earlier, heparanase and/or matrix metalloproteinases within the ECM may constitute innovative targets in the future as it has already been done in an Ewing sarcoma model (Cassinelli et al. 2013). A recent original study conducted by Li and Hanahan showed that glutamate and its receptor $\mathrm{N}$-methyl-D-aspartate receptor (NMDAR) was upregulated at the periphery of PNETs in RipTag2 mice, particularly invasive fronts, and that this invasivity was inhibited by the use of NMDAR inhibitor (Li \& Hanahan 2013).

An emerging concept in the future could be the combination of treatment targeting the tumor cell on the one hand, with those directed toward components of the ECM on the other hand. Moreover, by modulating the ECM, an improvement of the drug deliverance to the tumor niche is likely to occur as this was previously demonstrated (Olive et al. 2009).

\section{Summarizing conclusions}

The tumor and its microenvironment appear as two inseparable entities, which opens a new concept of pathophysiology and, therefore, require novel treatment strategies. Although significant progress have been achieved in the past years for treating GEP-NETs, a subset of patients will still experience treatment resistance or an escape after an initial period of remission. This issue is really challenging because it suggests the tumoral cell progressively adapts to or bypasses the therapeutic effect of a drug by activating alternative signaling pathways. The latter obviously occurs within the tumoral cell, but also results from the action of numerous ligands released 
within and by the components of the TME, a process called acquired resistance. Moreover, growing evidence from preclinical models indicates that when a tumor escapes from the treatment, a substantial modification of its behavior occurs, resulting in increased aggressiveness and a higher propensity to metastasize. Thus, understanding the impact of the TME in the tumor niche may lead not only to approaches to prevent treatment resistance, but also to prevent the emergence of an undifferentiated phenotype of the tumor.

It should be emphasized that many of the results of the studies reported in this review refer to animal models, which may be difficult to extrapolate to human GEP-NETs (Grozinsky-Glasberg et al. 2012). Moreover, relevant differences between GEP-NET cell lines have been recently emphasized by whole-exome sequencing and constitute another source of uncertainty when extrapolating results to the clinical setting (Vandamme et al. 2015). An alternative way could be studies on primary cultures of human GEP-NETs tumor, representing an affordable and individualized approach of the tumor biology and response to treatment from bench to bedside (Mohamed et al. 2017). Alternative options to optimally reproduce the in vivo landscape of the TME could be the use of microencapsulated SI-NET cells (Rokstad et al. 2012), as well as the development of animal models of spontaneous PNETs could be a solution (Yu 2016). In addition, 3D spheroid culturing of NET cells (Wong et al. 2012) or pheochromocytoma cells (D'Antongiovanni et al. 2017), allowing cell-cell interactions, have been successfully performed and give the possibility to perform histological, immunohistochemical and functional analysis and takes into consideration the tumor and its microenvironment.

For the elaboration of innovative therapeutical regimens (like the co-targeting strategy) and/or identification of new potential targets of GEP-NETs, it may be difficult to take into consideration the TME. Moreover, the TME of GEP-NETs is likely to change over the natural history of the tumor, under influence of the treatment, and from one tumor site to another. However, the development of whole proteomic as well as genomic approaches in the near future will undoubtedly help to delineate the TME of one given GEP-NET and possibly lead to combination treatments and sequential therapeutic schemes in order to overcome emerging resistance. Recent promising results on the genomics of PNETs (Scarpa et al. 2017) marked a step forward that will open perspectives in the understanding of the TME of such tumors.
Declaration of interest

L J Hofland, A Barlier and W W de Herder have received research grants from Ipsen and Novartis.

\section{Funding}

Thomas Cuny was the recipient of a fellowship supported by ITMO Cancer INSERM 'soutien pour la formation à la recherche translationnelle en cancérologie 2013' and a fellowship supported by SFE (Société Française d'Endocrinologie) 2012.

Author contribution statement

All authors significantly contributed to the content of this review.

\section{References}

Adams RL, Adams IP, Lindow SW \& Atkin SL 2004 Inhibition of endothelial proliferation by the somatostatin analogue SOM230. Clinical Endocrinology 61 431-436. (https://doi. org/10.1111/j.1365-2265.2004.02098.x)

Ahn HK, Choi JY, Kim K-M, Kim H, Choi S-H, Park SH, Park JO, Lim HY, Kang WK, Lee J et al. 2013 Phase II study of pazopanib monotherapy in metastatic gastroenteropancreatic neuroendocrine tumours. British Journal of Cancer 109 1414-1419. (https://doi.org/10.1038/ bjc.2013.470)

Albini A, Florio T, Giunciuglio D, Masiello L, Carlone S, Corsaro A, Thellung S, Cai T, Noonan DM \& Schettini G 1999 Somatostatin controls Kaposi's sarcoma tumor growth through inhibition of angiogenesis. FASEB Journal 13 647-655. (https://doi.org/10.1096/ fasebj.13.6.647)

Allen E, Walters IB \& Hanahan D 2011 Brivanib, a dual FGF/VEGF inhibitor, is active both first and second line against mouse pancreatic neuroendocrine tumors developing adaptive/evasive resistance to VEGF inhibition. Clinical Cancer Research 17 5299-5310. (https://doi.org/10.1158/1078-0432.CCR-10-2847)

Alonso-Gordoa T, Capdevila J \& Grande E 2014 GEP-NETs UPDATE: Biotherapy for neuroendocrine tumours. European Journal of Endocrinology 172 R31-R46. (https://doi.org/10.1530/EJE-14-0354)

Angelescu R, Burada F, Angelescu C, Gheonea DI, Iordache S, Mixich F, Ioana M \& Săftoiu A 2013 Expression of vascular endothelial growth factor and epidermal growth factor receptor in pancreatic ductal adenocarcinomas, neuroendocrine tumours and chronic pancreatitis. Endoscopic Ultrasound 2 86-91. (https://doi.org/10.4103/23039027.117692)

Arnold R, Rinke A, Klose K-J, Müller H-H, Wied M, Zamzow K, Schmidt C, Schade-Brittinger C, Barth P, Moll R et al. 2005 Octreotide versus octreotide plus interferon-alpha in endocrine gastroenteropancreatic tumors: a randomized trial. Clinical Gastroenterology and Hepatology : The Official Clinical Practice Journal of the American Gastroenterological Association 3 761-771. (https://doi. org/10.1016/S1542-3565(05)00481-7)

Beauchamp RD, Coffey RJ, Lyons RM, Perkett EA, Townsend CM \& Moses HL 1991 Human carcinoid cell production of paracrine growth factors that can stimulate fibroblast and endothelial cell growth. Cancer Research 51 5253-5260.

Bellmunt J, de Wit R, Vaughn DJ, Fradet Y, Lee J-L, Fong L, Vogelzang NJ, Climent MA, Petrylak DP, Choueiri TK, et al. 2017 Pembrolizumab as second-line therapy for advanced urothelial carcinoma. New England Journal of Medicine 376 1015-1026. (https:// doi.org/10.1056/NEJMoa1613683)

Bendell JC, Zakari A, Lang E, Waterhouse D, Flora D, Alguire K, McCleod M, Peacock N, Ruehlman P, Lane CM et al. 2016 A Phase II 
Study of the Combination of Bevacizumab, Pertuzumab, and Octreotide LAR for Patients with Advanced Neuroendocrine Cancers. Cancer Investigation 34 213-219. (https://doi.org/10.3109/07357907.2 016.1174257)

Bergers G \& Hanahan D 2008 Modes of resistance to anti-angiogenic therapy. Nature Reviews Cancer 8 592-603. (https://doi.org/10.1038/ nrc2442)

Bergers G, Javaherian K, Lo KM, Folkman J \& Hanahan D 1999 Effects of angiogenesis inhibitors on multistage carcinogenesis in mice. Science 284 808-812. (https://doi.org/10.1126/science.284.5415.808)

Bergestuen DS, Gravning J, Haugaa KH, Sahakyan LG, Aakhus S, ThiisEvensen E, Øie E, Aukrust P, Attramadal H \& Edvardsen T 2010 Plasma CCN2/connective tissue growth factor is associated with right ventricular dysfunction in patients with neuroendocrine tumors. BMC Cancer 10 6. (https://doi.org/10.1186/1471-2407-10-6)

Blattman JN \& Greenberg PD 2004 Cancer immunotherapy: a treatment for the masses. Science 305 200-205. (https://doi.org/10.1126/ science.1100369)

Blobe GC, Schiemann WP \& Lodish HF 2000 Role of transforming growth factor beta in human disease. New England Journal of Medicine 342 1350-1358. (https://doi.org/10.1056/NEJM200005043421807)

Bocci G, Culler MD, Fioravanti A, Orlandi P, Fasciani A, Colucci R, Taylor JE, Sadat D, Danesi R \& Del Tacca M 2007 In vitro antiangiogenic activity of selective somatostatin subtype-1 receptor agonists. European Journal of Clinical Investigation 37 700-708. (https://doi.org/10.1111/j.1365-2362.2007.01848.x)

Bollard J, Massoma P, Vercherat C, Blanc M, Lepinasse F, Gadot N, Couderc C, Poncet G, Walter T, Joly M-O, et al. 2015 The axon guidance molecule semaphorin $3 \mathrm{~F}$ is a negative regulator of tumor progression and proliferation in ileal neuroendocrine tumors. Oncotarget 6 36731-36745. (https://doi.org/10.18632/ oncotarget.5481)

Bowden M, Sicinska E, Kulke M \& Loda M 2014 Understanding the role of the carcinoid associated fibroblast in the neuroendocrine tumors microenvironment. Cancer Research 74 Abstract nr 168. (https://doi. org/10.1158/1538-7445)

Butcher DT, Alliston T \& Weaver VM 2009 A tense situation: forcing tumour progression. Nature Reviews Cancer 9 108-122. (https://doi org/10.1038/nrc2544)

Cao Y 2013 Multifarious functions of PDGFs and PDGFRs in tumor growth and metastasis. Trends in Molecular Medicine 19 460-473. (https://doi.org/10.1016/j.molmed.2013.05.002)

Cao Y 2014 VEGF-targeted cancer therapeutics-paradoxical effects in endocrine organs. Nature Reviews Endocrinology 10 530-539. (https:// doi.org/10.1038/nrendo.2014.114)

Cao R, Bråkenhielm E, Li X, Pietras K, Widenfalk J, Ostman A, Eriksson U \& Cao Y 2002 Angiogenesis stimulated by PDGF-CC, a novel member in the PDGF family, involves activation of PDGFRalphaalpha and -alphabeta receptors. FASEB Journal 16 1575-1583. (https://doi.org/10.1096/fj.02-0319com)

Caplin ME, Pavel M, Ćwikła JB, Phan AT, Raderer M, Sedláčková E, Cadiot G, Wolin EM, Capdevila J, Wall L et al. 2014 Lanreotide in metastatic enteropancreatic neuroendocrine tumors. The New England Journal of Medicine 371 224-233. (https://doi.org/ NEJMoa1316158)

Casanovas O, Hicklin DJ, Bergers G \& Hanahan D 2005 Drug resistance by evasion of antiangiogenic targeting of VEGF signaling in latestage pancreatic islet tumors. Cancer Cell 8 299-309. (https://doi. org/10.1016/j.ccr.2005.09.005)

Cassinelli G, Lanzi C, Tortoreto M, Cominetti D, Petrangolini G, Favini E, Zaffaroni N, Pisano C, Penco S, Vlodavsky I, et al. 2013 Antitumor efficacy of the heparanase inhibitor SST0001 alone and in combination with antiangiogenic agents in the treatment of human pediatric sarcoma models. Biochemical Pharmacology 85 1424-1432. (https://doi.org/10.1016/j.bcp.2013.02.023)
Castellano D, Capdevila J, Sastre J, Alonso V, Llanos M, GarcíaCarbonero R, Manzano Mozo JL, Sevilla I, Durán I \& Salazar R 2013 Sorafenib and bevacizumab combination targeted therapy in advanced neuroendocrine tumour: a phase II study of Spanish Neuroendocrine Tumour Group (GETNE0801). European Journal of Cancer (Oxford, England : 1990) 49 3780-3787. (https://doi. org/10.1016/j.ejca.2013.06.042)

Chaudhry A, Papanicolaou V, Oberg K, Heldin CH \& Funa K 1992 Expression of platelet-derived growth factor and its receptors in neuroendocrine tumors of the digestive system. Cancer Research $\mathbf{5 2}$ 1006-1012.

Chaudhry A, Funa K \& Oberg K 1993 Expression of growth factor peptides and their receptors in neuroendocrine tumors of the digestive system. Acta Oncologica 32 107-114. (https://doi. org/10.3109/02841869309083898)

Chaudhry A, Oberg K, Gobl A, Heldin CH \& Funa K 1994 Expression of transforming growth factors beta 1 , beta 2 , beta 3 in neuroendocrine tumors of the digestive system. Anticancer Research 14 2085-2091.

Chen L \& Han X 2015 Anti-PD-1/PD-L1 therapy of human cancer: past, present, and future. Journal of Clinical Investigation 125 3384-3391. (https://doi.org/10.1172/JCI80011)

Christofori G, Naik P \& Hanahan D 1995 Vascular endothelial growth factor and its receptors, flt- 1 and flk- 1 , are expressed in normal pancreatic islets and throughout islet cell tumorigenesis. Molecular Endocrinology 9 1760-1770. (https://doi.org/10.1210/ mend.9.12.8614412)

Cigrovski Berković M, Čačev T, Catela Ivković T, Marout J, Ulamec M, Zjačić-Rotkvić V \& Kapitanović S 2016 High VEGF serum values are associated with locoregional spread of gastroenteropancreatic neuroendocrine tumors (GEP-NETs). Molecular and Cellular Endocrinology 425 61-68. (https://doi.org/10.1016/j.mce.2016.01.013)

Cives M, Kunz PL, Morse B, Coppola D, Schell MJ, Campos T, Nguyen PT, Nandoskar P, Khandelwal V \& Strosberg JR 2015 Phase II clinical trial of pasireotide long-acting repeatable in patients with metastatic neuroendocrine tumors. Endocrine-Related Cancer 22 1-9. (https://doi.org/10.1530/ERC-14-0360)

Corti A 2010 Chromogranin A and the tumor microenvironment. Cellular and Molecular Neurobiology 30 1163-1170. (https://doi. org/10.1007/s10571-010-9587-8)

Cui C, Mao L, Chi Z, Si L, Sheng X, Kong Y, Li S, Lian B, Gu K, Tao M, et al. 2013 A phase II, randomized, double-blind, placebo-controlled multicenter trial of endostar in patients with metastatic melanoma. Molecular Therapy 21 1456-1463. (https://doi.org/10.1038/ $\mathrm{mt}$.2013.79)

Cunningham JL, Tsolakis AV, Jacobson A \& Janson ET 2010 Connective tissue growth factor expression in endocrine tumors is associated with high stromal expression of alpha-smooth muscle actin. European Journal of Endocrinology 163 691-697. (https://doi. org/10.1530/EJE-10-0420)

D'Antongiovanni V, Martinelli S, Richter S, Canu L, Guasti D, Mello T, Romagnoli P, Pacak K, Eisenhofer G, Mannelli M, et al. 2017 The microenvironment induces collective migration in SDHB-silenced mouse pheochromocytoma spheroids. Endocrine-Related Cancer $\mathbf{2 4}$ 555-564. (https://doi.org/10.1530/ERC-17-0212)

Dahan L, Bonnetain F, Rougier P, Raoul J-L, Gamelin E, Etienne P-L, Cadiot G, Mitry E, Smith D, Cvitkovic F et al. 2009 Phase III trial of chemotherapy using 5-fluorouracil and streptozotocin compared with interferon alpha for advanced carcinoid tumors: FNCLCC-FFCD 9710. Endocrine-Related Cancer 16 1351-1361. (https://doi. org/10.1677/ERC-09-0104)

Dasari A, Phan A, Gupta S, Rashid A, Yeung S-CJ, Hess K, Chen H, Tarco E, Chen H, Wei C et al. 2015 Phase I study of the anti-IGF1R antibody cixutumumab with everolimus and octreotide in advanced well-differentiated neuroendocrine tumors. Endocrine-Related Cancer 22 431-441. (https://doi.org/10.1530/ERC-15-0002)
(2) 2018 Society for Endocrinology Published by Bioscientifica Ltd. Printed in Great Britain 
Dasari A, Shen C, Halperin D, Zhao B, Zhou S, Xu Y, Shih T \& Yao JC 2017 Trends in the incidence, prevalence, and survival outcomes in patients with neuroendocrine tumors in the United States. JAMA Oncology 3 1335-1342. (https://doi.org/10.1001/ jamaoncol.2017.0589)

de Gramont A, Faivre S \& Raymond E 2017 Novel TGF- $\beta$ inhibitors ready for prime time in onco-immunology. Oncoimmunology 6 e1257453. (https://doi.org/10.1080/2162402X.2016.1257453)

Detjen KM, Welzel M, Farwig K, Brembeck FH, Kaiser A, Riecken EO, Wiedenmann B \& Rosewicz S 2000 Molecular mechanism of interferon alfa-mediated growth inhibition in human neuroendocrine tumor cells. Gastroenterology 118 735-748. (https:// doi.org/10.1016/S0016-5085(00)70143-0)

Detjen KM, Kehrberger JP, Drost A, Rabien A, Welzel M, Wiedenmann B \& Rosewicz S 2002 Interferon-gamma inhibits growth of human neuroendocrine carcinoma cells via induction of apoptosis. International Journal of Oncology 21 1133-1140.

Detjen KM, Rieke S, Deters A, Schulz P, Rexin A, Vollmer S, Hauff P, Wiedenmann B, Pavel M \& Scholz A 2010 Angiopoietin-2 promotes disease progression of neuroendocrine tumors. Clinical Cancer Research 16 420-429. (https://doi.org/10.1158/1078-0432.CCR-091924)

Drozdov I, Kidd M, Gustafsson BI, Svejda B, Joseph R, Pfragner R \& Modlin IM 2009 Autoregulatory effects of serotonin on proliferation and signaling pathways in lung and small intestine neuroendocrine tumor cell lines. Cancer 115 4934-4945. (https://doi.org/10.1002/ cncr.24533)

Druce M, Rockall A \& Grossman AB 2009 Fibrosis and carcinoid syndrome: from causation to future therapy. Nature Reviews Endocrinology 5 276-283. (https://doi.org/10.1038/nrendo.2009.51)

Durkin AJ, Bloomston M, Yeatman TJ, Gilbert-Barness E, Cojita D, Rosemurgy AS \& Zervos EE 2004 Differential expression of the Tie-2 receptor and its ligands in human pancreatic tumors. Journal of the American College of Surgeons 199 724-731. (https://doi.org/10.1016/j. jamcollsurg.2004.07.021)

Eklund L \& Saharinen P 2013 Angiopoietin signaling in the vasculature. Experimental Cell Research 319 1271-1280. (https://doi.org/10.1016/j. yexcr.2013.03.011)

Esser S, Wolburg K, Wolburg H, Breier G, Kurzchalia T \& Risau W 1998 Vascular endothelial growth factor induces endothelial fenestrations in vitro. Journal of Cell Biology 140 947-959. (https://doi. org/10.1083/jcb.140.4.947)

Feig C, Gopinathan A, Neesse A, Chan DS, Cook N \& Tuveson DA 2012 The pancreas cancer microenvironment. Clinical Cancer Research 18 4266-4276. (https://doi.org/10.1158/1078-0432.CCR-11-3114)

Felcht M, Luck R, Schering A, Seidel P, Srivastava K, Hu J, Bartol A, Kienast Y, Vettel C, Loos EK, et al. 2012 Angiopoietin-2 differentially regulates angiogenesis through TIE2 and integrin signaling. Journal of Clinical Investigation 122 1991-2005. (https://doi.org/10.1172/ JCI58832)

Ferrara N 2004 Vascular endothelial growth factor: basic science and clinical progress. Endocrine Reviews 25 581-611. (https://doi. org/10.1210/er.2003-0027)

Ferrero E, Scabini S, Magni E, Foglieni C, Belloni D, Colombo B, Curnis F, Villa A, Ferrero ME \& Corti A 2004 Chromogranin A protects vessels against tumor necrosis factor alpha-induced vascular leakage. FASEB Journal 18 554-556. (https://doi.org/10.1096/fj.030922fje)

Ferris RL, Blumenschein G, Fayette J, Guigay J, Colevas AD, Licitra L, Harrington K, Kasper S, Vokes EE, Even C, et al. 2016 Nivolumab for recurrent squamous-cell carcinoma of the head and neck. New England Journal of Medicine 375 1856-1867. (https://doi.org/10.1056/ NEJMoa1602252)

Figueroa-Vega N, Díaz A, Adrados M, Alvarez-Escolá C, Paniagua A, Aragonés J, Martín-Pérez E, Leskela S, Moreno-Otero R, GonzálezAmaro R, et al. 2010 The association of the angiopoietin/Tie-2 system with the development of metastasis and leukocyte migration in neuroendocrine tumors. Endocrine-Related Cancer 17 897-908. (https://doi.org/10.1677/ERC-10-0020)

Fischer C, Mazzone M, Jonckx B \& Carmeliet P 2008 FLT1 and its ligands VEGFB and PIGF: drug targets for anti-angiogenic therapy? Nature Reviews Cancer 8 942-956. (https://doi.org/10.1038/nrc2524)

Fjällskog M-LH, Lejonklou MH, Oberg KE, Eriksson BK \& Janson ET 2003 Expression of molecular targets for tyrosine kinase receptor antagonists in malignant endocrine pancreatic tumors. Clinical Cancer Research 9 1469-1473.

Fjällskog M-L, Hessman O, Eriksson B \& Janson ET 2007 Upregulated expression of PDGF receptor beta in endocrine pancreatic tumors and metastases compared to normal endocrine pancreas. Acta Oncologica 46 741-746. (https://doi. org/10.1080/02841860601048388)

Florio T, Morini M, Villa V, Arena S, Corsaro A, Thellung S, Culler MD, Pfeffer U, Noonan DM, Schettini G, et al. 2003 Somatostatin inhibits tumor angiogenesis and growth via somatostatin receptor-3mediated regulation of endothelial nitric oxide synthase and mitogen-activated protein kinase activities. Endocrinology 144 1574-1584. (https://doi.org/10.1210/en.2002-220949)

Folkman J, Watson K, Ingber D \& Hanahan D 1989 Induction of angiogenesis during the transition from hyperplasia to neoplasia. Nature 339 58-61. (https://doi.org/10.1038/339058a0)

Fredriksson L, Li H \& Eriksson U 2004 The PDGF family: four gene products form five dimeric isoforms. Cytokine and Growth Factor Reviews 15 197-204. (https://doi.org/10.1016/j. cytogfr.2004.03.007)

Funa K, Gazdar AF, Mattson K, Niiranen A, Koivuniemi A, Oberg K, Wilander E, Doyle A \& Linnoila RI 1986 Interferon-mediated in vivo induction of beta 2-microglobulin on small-cell lung cancers and mid-gut carcinoids. Clinical Immunology and Immunopathology $\mathbf{4 1}$ 159-164. (https://doi.org/10.1016/0090-1229(86)90060-7)

Funa K, Papanicolaou V, Juhlin C, Rastad J, Akerström G, Heldin CH \& Oberg K 1990 Expression of platelet-derived growth factor betareceptors on stromal tissue cells in human carcinoid tumors. Cancer Research 50 748-753.

Furukawa M, Raffeld M, Mateo C, Sakamoto A, Moody TW, Ito T, Venzon DJ, Serrano J \& Jensen RT 2005 Increased expression of insulin-like growth factor I and/or its receptor in gastrinomas is associated with low curability, increased growth, and development of metastases. Clinical Cancer Research 11 3233-3242. (https://doi. org/10.1158/1078-0432.CCR-04-1915)

García-Suárez O, García B, Fernández-Vega I, Astudillo A \& Quirós LM 2014 Neuroendocrine tumors show altered expression of chondroitin sulfate, glypican 1 , glypican 5 , and syndecan 2 depending on their differentiation grade. Frontiers in Oncology 4 15. (https://doi. org/10.3389/fonc.2014.00015)

Ghiotto M, Gauthier L, Serriari N, Pastor S, Truneh A, Nunès JA \& Olive D 2010 PD-L1 and PD-L2 differ in their molecular mechanisms of interaction with PD-1. International Immunology 22 651-660. (https://doi.org/10.1093/intimm/dxq049)

Giovinazzo F, Schimmack S, Svejda B, Alaimo D, Pfragner R, Modlin I \& Kidd M 2013 Chromogranin A and its fragments as regulators of small intestinal neuroendocrine neoplasm proliferation. PLOS ONE $\mathbf{8}$ e81111. (https://doi.org/10.1371/journal.pone.0081111)

Grande E, Capdevila J, Castellano D, Teulé A, Durán I, Fuster J, Sevilla I, Escudero P, Sastre J, García-Donas J et al. 2015 Pazopanib in pretreated advanced neuroendocrine tumors: a phase II, open-label trial of the Spanish Task Force Group for Neuroendocrine Tumors (GETNE). Annals of Oncology : Official Journal of the European Society for Medical Oncology / ESMO 26 1987-1993. (https://doi.org/10.1093/ annonc/mdv252)

Grotendorst GR 1997 Connective tissue growth factor: a mediator of TGF-beta action on fibroblasts. Cytokine and Growth Factor Reviews $\mathbf{8}$ 171-179. (https://doi.org/10.1016/S1359-6101(97)00010-5) 
Grozinsky-Glasberg S, Shimon I \& Rubinfeld H 2012 The role of cell lines in the study of neuroendocrine tumors. Neuroendocrinology 96 173-187. (https://doi.org/10.1159/000338793)

Hallet J, Law CHL, Cukier M, Saskin R, Liu N \& Singh S 2014 Exploring the rising incidence of neuroendocrine tumors: a population-based analysis of epidemiology, metastatic presentation, and outcomes. Cancer 121 589-597. (https://doi.org/10.1002/cncr.29099)

Hanahan D \& Weinberg RA 2011 Hallmarks of cancer: the next generation. Cell 144 646-674. (https://doi.org/10.1016/j. cell.2011.02.013)

Hauso O, Gustafsson BI, Kidd M, Waldum HL, Drozdov I, Chan AKC \& Modlin IM 2008 Neuroendocrine tumor epidemiology: contrasting Norway and North America. Cancer 113 2655-2664. (https://doi. org/10.1002/cncr.23883)

Herbertz S, Sawyer JS, Stauber AJ, Gueorguieva I, Driscoll KE, Estrem ST, Cleverly AL, Desaiah D, Guba SC, Benhadji KA, et al. 2015 Clinical development of galunisertib (LY2157299 monohydrate), a small molecule inhibitor of transforming growth factor-beta signaling pathway. Drug Design, Development and Therapy 9 4479-4499. (https://doi.org/10.2147/DDDT.S86621)

Hilfenhaus G, Göhrig A, Pape U-F, Neumann T, Jann H, Zdunek D, Hess G, Stassen JM, Wiedenmann B, Detjen K, et al. 2013 Placental growth factor supports neuroendocrine tumor growth and predicts disease prognosis in patients. Endocrine-Related Cancer 20 305-319. (https://doi.org/10.1530/ERC-12-0223)

Hobday TJ, Rubin J, Holen K, Picus J, Donehower R, Marschke R, Maples W, Lloyd R, Mahoney M \& Erlichman C 2007 MC044h, a phase II trial of sorafenib in patients (pts) with metastatic neuroendocrine tumors (NET): A Phase II Consortium (P2C) study. ASCO Meeting Abstracts 254504.

Hobday TJ, Qin R, Reidy-Lagunes D, Moore MJ, Strosberg J, Kaubisch A, Shah M, Kindler HL, Lenz H-J, Chen H et al. 2015 Multicenter Phase II Trial of Temsirolimus and Bevacizumab in Pancreatic Neuroendocrine Tumors. Journal of Clinical Oncology : Official Journal of the American Society of Clinical Oncology 33 1551-1556. (https:// doi.org/10.1200/JCO.2014.56.2082)

Höpfner M, Baradari V, Huether A, Schöfl C \& Scherübl H 2006 The insulin-like growth factor receptor 1 is a promising target for novel treatment approaches in neuroendocrine gastrointestinal tumours. Endocrine-Related Cancer 13 135-149. (https://doi.org/10.1677/ erc.1.01090)

Hunter KE, Palermo C, Kester JC, Simpson K, Li J-P, Tang LH, Klimstra DS, Vlodavsky I \& Joyce JA 2014 Heparanase promotes lymphangiogenesis and tumor invasion in pancreatic neuroendocrine tumors. Oncogene 33 1799-1808. (https://doi. org/10.1038/onc.2013.142)

Inai T, Mancuso M, Hashizume H, Baffert F, Haskell A, Baluk P, Hu-Lowe DD, Shalinsky DR, Thurston G, Yancopoulos GD, et al. 2004 Inhibition of vascular endothelial growth factor (VEGF) signaling in cancer causes loss of endothelial fenestrations, regression of tumor vessels, and appearance of basement membrane ghosts. American Journal of Pathology 165 35-52. (https://doi. org/10.1016/S0002-9440(10)63273-7)

Inoue M, Hager JH, Ferrara N, Gerber H-P \& Hanahan D 2002 VEGF-A has a critical, nonredundant role in angiogenic switching and pancreatic beta cell carcinogenesis. Cancer Cell 1 193-202. (https:// doi.org/10.1016/S1535-6108(02)00031-4)

Itakura J, Ishiwata T, Shen B, Kornmann M \& Korc M 2000 Concomitant over-expression of vascular endothelial growth factor and its receptors in pancreatic cancer. International Journal of Cancer $\mathbf{8 5}$ 27-34. (https://doi.org/10.1002/(SICI)10970215(20000101)85:1<27::AID-IJC5>3.0.CO;2-8)

Ito T, Sasano H, Tanaka M, Osamura RY, Sasaki I, Kimura W, Takano K, Obara T, Ishibashi M, Nakao K, et al. 2010 Epidemiological study of gastroenteropancreatic neuroendocrine tumors in Japan. Journal of
Gastroenterology 45 234-243. (https://doi.org/10.1007/s00535-0090194-8)

Jacobetz MA, Chan DS, Neesse A, Bapiro TE, Cook N, Frese KK, Feig C, Nakagawa T, Caldwell ME, Zecchini HI, et al. 2013 Hyaluronan impairs vascular function and drug delivery in a mouse model of pancreatic cancer. Gut 62 112-120. (https://doi.org/10.1136/ gutjnl-2012-302529)

Jiao Y, Shi C, Edil BH, de Wilde RF, Klimstra DS, Maitra A, Schulick RD, Tang LH, Wolfgang CL, Choti MA, et al. 2011 DAXX/ATRX, MEN1, and mTOR pathway genes are frequently altered in pancreatic neuroendocrine tumors. Science 331 1199-1203. (https://doi. org/10.1126/science.1200609)

Joyce JA, Freeman C, Meyer-Morse N, Parish CR \& Hanahan D 2005 A functional heparan sulfate mimetic implicates both heparanase and heparan sulfate in tumor angiogenesis and invasion in a mouse model of multistage cancer. Oncogene 24 4037-4051. (https://doi. org/10.1038/sj.onc.1208602)

Kalluri R \& Zeisberg M 2006 Fibroblasts in cancer. Nature Reviews Cancer 6 392-401. (https://doi.org/10.1038/nrc1877)

Kaltsas GA, Cunningham JL, Falkmer SE, Grimelius L \& Tsolakis AV 2011 Expression of connective tissue growth factor and IGF1 in normal and neoplastic gastrointestinal neuroendocrine cells and their clinico-pathological significance. Endocrine-Related Cancer 18 61-71. (https://doi.org/10.1677/ERC-10-0026)

Kanno S, Oda N, Abe M, Terai Y, Ito M, Shitara K, Tabayashi K, Shibuya M \& Sato Y 2000 Roles of two VEGF receptors, Flt-1 and $\mathrm{KDR}$, in the signal transduction of VEGF effects in human vascular endothelial cells. Oncogene 19 2138-2146. (https://doi.org/10.1038/ sj.onc.1203533)

Karar J \& Maity A 2011 PI3K/AKT/mTOR pathway in angiogenesis. Frontiers in Molecular Neuroscience 4 51. (https://doi.org/10.3389/ fnmol.2011.00051)

Katsenelson NS, Shurin G V, Bykovskaia SN, Shogan J \& Shurin MR 2001 Human small cell lung carcinoma and carcinoid tumor regulate dendritic cell maturation and function. Modern Pathology 14 40-45. (https://doi.org/10.1038/modpathol.3880254)

Katz S, Donkor C, Glasgow K, Pillarisetty V, Gönen M, Espat N, Klimstra D, D'Angelica M, Allen P, Jarnagin W, et al. $2010 \mathrm{~T}$ cell infiltrate and outcome following resection of intermediate-grade primary neuroendocrine tumours and liver metastases. HPB 12 674-683. (https://doi.org/10.1111/j.1477-2574.2010.00231.x)

Kessenbrock K, Plaks V \& Werb Z 2010 Matrix metalloproteinases: regulators of the tumor microenvironment. Cell 141 52-67. (https:// doi.org/10.1016/j.cell.2010.03.015)

Kidd M, Modlin IM, Pfragner R, Eick GN, Champaneria MC, Chan AK, Camp RL \& Mane SM 2007a Small bowel carcinoid (enterochromaffin cell) neoplasia exhibits transforming growth factor-beta1-mediated regulatory abnormalities including up-regulation of C-Myc and MTA1. Cancer 109 2420-2431. (https:// doi.org/10.1002/cncr.22725)

Kidd M, Modlin IM, Shapiro MD, Camp RL, Mane SM, Usinger W \& Murren JR 2007b CTGF, intestinal stellate cells and carcinoid fibrogenesis. World Journal of Gastroenterology 13 5208-5216. (https:// doi.org/10.3748/wjg.v13.i39.5208)

Kim ST, Ha SY, Lee S, Ahn S, Lee J, Park SH, Park JO, Lim HY, Kang WK, Kim K-M, et al. 2016 The impact of PD-L1 expression in patients with metastatic GEP-NETs. Journal of Cancer 7 484-489. (https://doi. org/10.7150/jca.13711)

Kimura N, Yoshida R, Shiraishi S, Pilichowska M \& Ohuchi N 2002 Chromogranin A and chromogranin B in noninvasive and invasive breast carcinoma. Endocrine Pathology 13 117-122. (https://doi. org/10.1385/EP:13:2:117)

Klöppel G 2011 Classification and pathology of gastroenteropancreatic neuroendocrine neoplasms. Endocrine-Related Cancer 18 (Supplement 1) S1-S16. (https://doi.org/10.1530/ERC-11-0013)
(2) 2018 Society for Endocrinology Published by Bioscientifica Ltd. Printed in Great Britain 
Kölby L, Persson G, Franzén S \& Ahrén B 2003 Randomized clinical trial of the effect of interferon alpha on survival in patients with disseminated midgut carcinoid tumours. The British Journal of Surgery 90 687-693. (https://doi.org/10.1002/bjs.4149)

Krishnamurthy S \& Dayal Y 1997 Immunohistochemical expression of transforming growth factor alpha and epidermal growth factor receptor in gastrointestinal carcinoids. American Journal of Surgical Pathology 21 327-333. (https://doi.org/10.1097/00000478199703000-00009)

Kulke MH 2007 Gastrointestinal neuroendocrine tumors: a role for targeted therapies? Endocrine-Related Cancer 14 207-219. (https://doi. org/10.1677/ERC-06-0061)

Kulke MH, Bergsland EK, Ryan DP, Enzinger PC, Lynch TJ, Zhu AX, Meyerhardt JA, Heymach JV, Fogler WE, Sidor C, et al. 2006 Phase II study of recombinant human endostatin in patients with advanced neuroendocrine tumors. Journal of Clinical Oncology 24 3555-3561. (https://doi.org/10.1200/JCO.2006.05.6762)

Kulke MH, O'Dorisio T, Phan A, Bergsland E, Law L, Banks P, Freiman J, Frazier K, Jackson J, Yao JC, et al. 2014 Telotristat etiprate, a novel serotonin synthesis inhibitor, in patients with carcinoid syndrome and diarrhea not adequately controlled by octreotide. EndocrineRelated Cancer 21 705-714. (https://doi.org/10.1530/ERC-14-0173)

Kulke MH, Hörsch D, Caplin ME, Anthony LB, Bergsland E, Öberg K, Welin S, Warner RRP, Lombard-Bohas C, Kunz PL, et al. 2017 Telotristat ethyl, a tryptophan hydroxylase inhibitor for the treatment of carcinoid syndrome. Journal of Clinical Oncology $\mathbf{3 5}$ 14-23. (https://doi.org/10.1200/JCO.2016.69.2780)

Kuroda M, Oka T, Oka Y, Yamochi T, Ohtsubo K, Mori S, Watanabe T, Machinami R \& Ohnishi S 1995 Colocalization of vascular endothelial growth factor (vascular permeability factor) and insulin in pancreatic islet cells. Journal of Clinical Endocrinology and Metabolism 80 3196-3200. (https://doi.org/10.1210/ jcem.80.11.7593426)

La Rosa S, Uccella S, Finzi G, Albarello L, Sessa F \& Capella C 2003 Localization of vascular endothelial growth factor and its receptors in digestive endocrine tumors: correlation with microvessel density and clinicopathologic features. Human Pathology 34 18-27. (https:// doi.org/10.1053/hupa.2003.56)

Landerholm K, Falkmer S \& Järhult J 2010 Epidemiology of small bowel carcinoids in a defined population. World Journal of Surgery 34 1500-1505. (https://doi.org/10.1007/s00268-010-0519-z)

Lawrence B, Gustafsson BI, Chan A, Svejda B, Kidd M \& Modlin IM 2011 The epidemiology of gastroenteropancreatic neuroendocrine tumors. Endocrinology and Metabolism Clinics of North America 40 1-18, vii. (https://doi.org/10.1016/j.ecl.2010.12.005)

Lee J-S, Kang J-H, Boo H-J, Hwang S-J, Hong S, Lee S-C, Park Y-J, Chung T-M, Youn H, Lee SM, et al. 2015 STAT3-mediated IGF-2 secretion in the tumour microenvironment elicits innate resistance to anti-IGF-1R antibody. Nature Communications 6 8499. (https://doi. org/10.1038/ncomms9499)

Leu FP, Nandi M \& Niu C 2008 The effect of transforming growth factor beta on human neuroendocrine tumor BON cell proliferation and differentiation is mediated through somatostatin signaling. Molecular Cancer Research 6 1029-1042. (https://doi.org/10.1158/1541-7786. MCR-07-2073)

Lewis CE \& Pollard JW 2006 Distinct role of macrophages in different tumor microenvironments. Cancer Research 66 605-612. (https://doi. org/10.1158/0008-5472.CAN-05-4005)

Li L \& Hanahan D 2013 Hijacking the neuronal NMDAR signaling circuit to promote tumor growth and invasion. Cell 153 86-100. (https://doi.org/10.1016/j.cell.2013.02.051)

Liu M, Kilarski WW, Gerwins P, Öberg K \& Zhou Y 2006 Efficient human interferon- $\alpha$ gene transfer to neuroendocrine tumor cells with long-term and stable expression. Neuroendocrinology $\mathbf{8 2}$ 264-273. (https://doi.org/10.1159/000092862)
Mancuso MR, Davis R, Norberg SM, O'Brien S, Sennino B, Nakahara T, Yao VJ, Inai T, Brooks P, Freimark B, et al. 2006 Rapid vascular regrowth in tumors after reversal of VEGF inhibition. Journal of Clinical Investigation 116 2610-2621. (https://doi.org/10.1172/ JCI24612)

Mergler S, Strauss O, Strowski M, Prada J, Drost A, Langrehr J, Neuhaus P, Wiedenmann B \& Ploeckinger U 2005 Insulin-like growth factor-1 increases intracellular calcium concentration in human primary neuroendocrine pancreatic tumor cells and a pancreatic neuroendocrine tumor cell line (BON-1) via R-type Ca2+ channels and regulates chromogranin a secretion in $\mathrm{BO}$. Neuroendocrinology 82 87-102. (https://doi.org/10.1159/000091008)

Mirvis E, Mandair D, Garcia-Hernandez J, Mohmaduvesh M, Toumpanakis C \& Caplin M 2014 Role of interferon-alpha in patients with neuroendocrine tumors: a retrospective study. Anticancer Research 34 6601-6607.

Modlin IM, Oberg K, Chung DC, Jensen RT, De Herder WW, Thakker RV, Caplin M, Fave GD, Kaltsas GA, Krenning EP, et al. 2008 Gastroenteropancreatic neuroendocrine tumours. Lancet Oncology 9 61-72. (https://doi.org/10.1016/S1470-2045(07)70410-2)

Mohamed A, Romano D, Saveanu A, Roche C, Albertelli M, Barbieri F, Brue T, Niccoli P, Delpero J-R, Garcia S, et al. 2017 Anti-proliferative and anti-secretory effects of everolimus on human pancreatic neuroendocrine tumors primary cultures: is there any benefit from combination with somatostatin analogs? Oncotarget 8 41044-41063. (https://doi.org/10.18632/oncotarget.17008)

Moussad EE \& Brigstock DR 2000 Connective tissue growth factor: what's in a name? Molecular Genetics and Metabolism 71 276-292. (https://doi.org/10.1006/mgme.2000.3059)

Nemecek GM, Coughlin SR, Handley DA \& Moskowitz MA 1986 Stimulation of aortic smooth muscle cell mitogenesis by serotonin. PNAS 83 674-678. (https://doi.org/10.1073/pnas.83.3.674)

Neufeld G, Shraga-Heled N, Lange T, Guttmann-Raviv N, Herzog Y \& Kessler O 2005 Semaphorins in cancer. Frontiers in Bioscience 10 751-760. (https://doi.org/10.2741/1569)

Nilsson O, Wängberg B, Kölby L, Schultz GS \& Ahlman H 1995 Expression of transforming growth factor alpha and its receptor in human neuroendocrine tumours. International Journal of Cancer $\mathbf{6 0}$ 645-651. (https://doi.org/10.1002/ijc.2910600514)

Olive KP, Jacobetz MA, Davidson CJ, Gopinathan A, McIntyre D, Honess D, Madhu B, Goldgraben MA, Caldwell ME, Allard D, et al. 2009 Inhibition of Hedgehog signaling enhances delivery of chemotherapy in a mouse model of pancreatic cancer. Science $\mathbf{3 2 4}$ 1457-1461. (https://doi.org/10.1126/science.1171362)

Onoyama M, Kitadai Y, Tanaka Y, Yuge R, Shinagawa K, Tanaka S, Yasui W \& Chayama K 2013 Combining molecular targeted drugs to inhibit both cancer cells and activated stromal cells in gastric cancer. Neoplasia 15 1391-1399. (https://doi.org/10.1593/neo.131668)

O’Toole D, Kianmanesh R \& Caplin M 2016 ENETS 2016 Consensus Guidelines for the management of patients with digestive neuroendocrine tumours: an update. Neuroendocrinology $\mathbf{1 0 3}$ 117-118. (https://doi.org/10.1159/000443169)

Parr C, Watkins G, Boulton M, Cai J \& Jiang WG 2005 Placenta growth factor is over-expressed and has prognostic value in human breast cancer. European Journal of Cancer 41 2819-2827. (https://doi. org/10.1016/j.ejca.2005.07.022)

Partelli S, Bartsch DK, Capdevila J, Chen J, Knigge U, Niederle B, Nieveen van Dijkum EJM, Pape U-F, Pascher A, Ramage J, et al. 2017 ENETS Consensus Guidelines for standard of care in neuroendocrine tumours: surgery for small intestinal and pancreatic neuroendocrine tumours. Neuroendocrinology 105 255-265. (https://doi. org/10.1159/000464292)

Pavel ME, Hassler G, Baum U, Hahn EG, Lohmann T \& Schuppan D 2005 Circulating levels of angiogenic cytokines can predict tumour progression and prognosis in neuroendocrine carcinomas. Clinical
C 2018 Society for Endocrinology Published by Bioscientifica Ltd. Printed in Great Britain 
Endocrinology 62 434-443. (https://doi. org/10.1111/j.1365-2265.2005.02238.x)

Pavel ME, Hainsworth JD, Baudin E, Peeters M, Hörsch D, Winkler RE, Klimovsky J, Lebwohl D, Jehl V, Wolin EM et al. 2011 Everolimus plus octreotide long-acting repeatable for the treatment of advanced neuroendocrine tumours associated with carcinoid syndrome (RADIANT-2): a randomised, placebo-controlled, phase 3 study. Lancet 378 2005-2012. (https://doi.org/10.1016/S01406736(11)61742-X)

Pavel M, Hörsch D, Caplin M, Ramage J, Seufferlein T, Valle J, Banks P, Lapuerta P, Sands A, Zambrowicz B, et al. 2015 Telotristat etiprate for carcinoid syndrome: a single-arm, multicenter trial. Journal of Clinical Endocrinology and Metabolism 100 1511-1519. (https://doi. org/10.1210/jc.2014-2247)

Phan AT, Halperin DM, Chan JA, Fogelman DR, Hess KR, Malinowski P, Regan E, Ng CS, Yao JC \& Kulke MH 2015 Pazopanib and depot octreotide in advanced, well-differentiated neuroendocrine tumours: a multicentre, single-group, phase 2 study. The Lancet. Oncology 16 695-703. (https://doi.org/10.1016/S1470-2045(15)70136-1)

Pickup M, Novitskiy S \& Moses HL 2013 The roles of TGF $\beta$ in the tumour microenvironment. Nature Reviews Cancer 13 788-799. (https://doi.org/10.1038/nrc3603)

Pietras K \& Hanahan D 2005 A multitargeted, metronomic, and maximum-tolerated dose 'chemo-switch' regimen is antiangiogenic, producing objective responses and survival benefit in a mouse model of cancer. Journal of Clinical Oncology 23 939-952. (https://doi. org/10.1200/JCO.2005.07.093)

Poncet G, Villaume K, Walter T, Pourreyron C, Theillaumas A, Lépinasse F, Hervieu V, Cordier-Bussat M, Scoazec J-Y \& Roche C 2009 Angiogenesis and tumor progression in neuroendocrine digestive tumors. Journal of Surgical Research 154 68-77. (https://doi. org/10.1016/j.jss.2008.03.055)

Prud'homme GJ \& Glinka Y 2012 Neuropilins are multifunctional coreceptors involved in tumor initiation, growth, metastasis and immunity. Oncotarget 3 921-939. (https://doi.org/10.18632/ oncotarget.626)

Pusceddu S, De Braud F, Lo Russo G, Concas L, Femia D, Vernieri C, Indini A, Formisano B \& Buzzoni R 2016 How do the results of the RADIANT trials impact on the management of NET patients? A systematic review of published studies. Oncotarget $744841-44847$. (https://doi.org/10.18632/oncotarget.8601)

Pyonteck SM, Gadea BB, Wang H-W, Gocheva V, Hunter KE, Tang LH \& Joyce JA 2012 Deficiency of the macrophage growth factor CSF-1 disrupts pancreatic neuroendocrine tumor development. Oncogene $\mathbf{3 1}$ 1459-1467. (https://doi.org/10.1038/onc.2011.337)

Raymond E, Dahan L, Raoul J-L, Bang Y-J, Borbath I, Lombard-Bohas C, Valle J, Metrakos P, Smith D, Vinik A, et al. 2011 Sunitinib malate for the treatment of pancreatic neuroendocrine tumors. New England Journal of Medicine 364 501-513. (https://doi.org/10.1056/ NEJMoa1003825)

Reck M, Rodríguez-Abreu D, Robinson AG, Hui R, Csőszi T, Fülöp A, Gottfried M, Peled N, Tafreshi A, Cuffe S, et al. 2016 Pembrolizumab versus chemotherapy for PD-L1-positive non-small-cell lung cancer. New England Journal of Medicine 375 1823-1833. (https://doi. org/10.1056/NEJMoa1606774)

Reidy-Lagunes DL, Vakiani E, Segal MF, Hollywood EM, Tang LH, Solit DB, Pietanza MC, Capanu M \& Saltz LB 2012 A phase 2 study of the insulin-like growth factor-1 receptor inhibitor MK-0646 in patients with metastatic, well-differentiated neuroendocrine tumors. Cancer 118 4795-4800. (https://doi.org/10.1002/cncr.27459)

Rinke A, Müller H-H, Schade-Brittinger C, Klose K-J, Barth P, Wied M, Mayer C, Aminossadati B, Pape U-F, Bläker M et al. 2009 Placebocontrolled, double-blind, prospective, randomized study on the effect of octreotide LAR in the control of tumor growth in patients with metastatic neuroendocrine midgut tumors: a report from the PROMID Study Group. Journal of Clinical Oncology : Official Journal of the American Society of Clinical Oncology 27 4656-4663. (https://doi. org/JCO.2009.22.8510)

Risau W 1997 Mechanisms of angiogenesis. Nature 386 671-674. (https://doi.org/10.1146/annurev.physiol.49.1.453)

Risau W, Drexler H, Mironov V, Smits A, Siegbahn A, Funa K \& Heldin CH 1992 Platelet-derived growth factor is angiogenic in vivo. Growth Factors 7 261-266. (https://doi. org/10.3109/08977199209046408)

Roberts AB \& Wakefield LM 2003 The two faces of transforming growth factor in carcinogenesis. PNAS 100 8621-8623. (https://doi. org/10.1073/pnas.1633291100)

Rokstad AM, Gustafsson BI, Espevik T, Bakke I, Pfragner R, Svejda B, Modlin IM \& Kidd M 2012 Microencapsulation of small intestinal neuroendocrine neoplasm cells for tumor model studies. Cancer Science 103 1230-1237. (https://doi. org/10.1111/j.1349-7006.2012.02282.x)

Ryschich E, Autschbach F, Eisold S, Klar E, Buchler MW \& Schmidt J 2003 Expression of HLA class I/II antigens and T cell immune response in human neuroendocrine tumors of the pancreas. Tissue Antigens 62 48-54. (https://doi. org/10.1034/j.1399-0039.2003.00075.x)

Scarpa A, Chang DK, Nones K, Corbo V, Patch A-M, Bailey P, Lawlor RT, Johns AL, Miller DK, Mafficini A, et al. 2017 Whole-genome landscape of pancreatic neuroendocrine tumours. Nature 543 65-71. (https://doi.org/10.1038/nature21063)

Scoazec J-Y 2005 Endocrine tumors: biology and physiopathology. Annales de Pathologie 25 447-461. (https://doi.org/10.1016/S02426498(05)86160-7)

Scoazec J-Y 2013 Angiogenesis in neuroendocrine tumors: therapeutic applications. Neuroendocrinology 97 45-56. (https://doi org/10.1159/000338371)

Semenza GL 1998 Hypoxia-inducible factor 1: master regulator of O2 homeostasis. Current Opinion in Genetics and Development 8 588-594. (https://doi.org/10.1016/S0959-437X(98)80016-6)

Sennino B, Ishiguro-Oonuma T, Wei Y, Naylor RM, Williamson CW, Bhagwandin V, Tabruyn SP, You W-K, Chapman HA, Christensen JG, et al. 2012 Suppression of tumor invasion and metastasis by concurrent inhibition of c-Met and VEGF signaling in pancreatic neuroendocrine tumors. Cancer Discovery 2 270-287. (https://doi. org/10.1158/2159-8290.CD-11-0240)

Sennino B, Ishiguro-Oonuma T, Schriver BJ, Christensen JG \& McDonald DM 2013 Inhibition of c-Met reduces lymphatic metastasis in RIP-Tag2 transgenic mice. Cancer Research $\mathbf{7 3}$ 3692-3703. (https://doi.org/10.1158/0008-5472.CAN-12-2160)

Seuwen K, Magnaldo I \& Pouysségur J 1988 Serotonin stimulates DNA synthesis in fibroblasts acting through 5 -HT1B receptors coupled to a Gi-protein. Nature 335 254-256. (https://doi. org $/ 10.1038 / 335254 \mathrm{a} 0$ )

Shchors K, Nozawa H, Xu J, Rostker F, Swigart-Brown L, Evan G \& Hanahan D 2013 Increased invasiveness of MMP-9-deficient tumors in two mouse models of neuroendocrine tumorigenesis. Oncogene 32 502-513. (https://doi.org/10.1038/onc.2012.60)

Shojaei F \& Ferrara N 2008 Role of the microenvironment in tumor growth and in refractoriness/resistance to anti-angiogenic therapies. Drug Resistance Updates 11 219-230. (https://doi.org/10.1016/j. drup.2008.09.001)

Siddique Z-L, Drozdov I, Floch J, Gustafsson BI, Stunes K, Pfragner R, Kidd M \& Modlin IM 2009 KRJ-I and BON cell lines: defining an appropriate enterochromaffin cell neuroendocrine tumor model. Neuroendocrinology 89 458-470. (https://doi.org/10.1159/000209330)

Soucek L, Lawlor ER, Soto D, Shchors K, Swigart LB \& Evan GI 2007 Mast cells are required for angiogenesis and macroscopic expansion of Myc-induced pancreatic islet tumors. Nature Medicine $\mathbf{1 3}$ 1211-1218. (https://doi.org/10.1038/nm1649)

Soucek L, Buggy JJ, Kortlever R, Adimoolam S, Monclús HA, Allende MTS, Swigart LB \& Evan GI 2011 Modeling pharmacological (c) 2018 Society for Endocrinology Published by Bioscientifica Ltd. Printed in Great Britain 
inhibition of mast cell degranulation as a therapy for insulinoma. Neoplasia 13 1093-1100. (https://doi.org/10.1593/neo.11980)

Srirajaskanthan R, Dancey G, Hackshaw A, Luong T, Caplin ME \& Meyer T 2009 Circulating angiopoietin-2 is elevated in patients with neuroendocrine tumours and correlates with disease burden and prognosis. Endocrine-Related Cancer 16 967-976. (https://doi. org/10.1677/ERC-09-0089)

Srivastava A, Alexander J, Lomakin I \& Dayal Y 2001 Immunohistochemical expression of transforming growth factor alpha and epidermal growth factor receptor in pancreatic endocrine tumors. Human Pathology 32 1184-1189. (https://doi.org/10.1053/ hupa.2001.28959)

Straussman R, Morikawa T, Shee K, Barzily-Rokni M, Qian ZR, Du J, Davis A, Mongare MM, Gould J, Frederick DT, et al. 2012 Tumour micro-environment elicits innate resistance to RAF inhibitors through HGF secretion. Nature 487 500-504. (https://doi. org/10.1038/nature11183)

Strosberg JR, Chan JA, Ryan DP, Meyerhardt JA, Fuchs CS, Abrams T, Regan E, Brady R, Weber J, Campos T et al. 2013 A multiinstitutional, phase II open-label study of ganitumab (AMG 479) in advanced carcinoid and pancreatic neuroendocrine tumors. Endocrine-Related Cancer 20 383-390. (https://doi.org/10.1530/ERC12-0390)

Strosberg JR, Cives M, Hwang J, Weber T, Nickerson M, Atreya CE, Venook A, Kelley RK, Valone T, Morse B et al. 2016 A phase II study of axitinib in advanced neuroendocrine tumors. Endocrine-Related Cancer 23 411-418. (https://doi.org/10.1530/ERC-16-0008)

Strosberg JR, El-Haddad G, Wolin E, Hendifar A, Yao J, Chasen B, Mittra E, Kunz PL, Kulke MH, Jacene H et al. 2017 Phase 3 Trial of 177Lu-dotatate for midgut neuroendocrine tumors. The New England Journal of Medicine 376 125-135. (https://doi.org/10.1056/ NEJMoa1607427)

Svejda B, Kidd M, Giovinazzo F, Eltawil K, Gustafsson BI, Pfragner R \& Modlin IM 2010 The 5-HT(2B) receptor plays a key regulatory role in both neuroendocrine tumor cell proliferation and the modulation of the fibroblast component of the neoplastic microenvironment. Cancer 116 2902-2912. (https://doi.org/10.1002/cncr.25049)

Taghavi S, Jayarajan SN, Powers BD, Davey A \& Willis AI 2013 Examining rectal carcinoids in the era of screening colonoscopy: a surveillance, epidemiology, and end results analysis. Diseases of the Colon and Rectum 56 952-959. (https://doi.org/10.1097/ DCR.0b013e318291f512)

Terris B, Scoazec JY, Rubbia L, Bregeaud L, Pepper MS, Ruszniewski P, Belghiti J, Fléjou J \& Degott C 1998 Expression of vascular endothelial growth factor in digestive neuroendocrine tumours. Histopathology 32 133-138. (https://doi. org/10.1046/j.1365-2559.1998.00321.x)

Theoharides TC 2008 Mast cells and pancreatic cancer. New England Journal of Medicine 358 1860-1861. (https://doi.org/10.1056/ NEJMcibr0801519)

Tijeras-Raballand A, Neuzillet C, Couvelard A, Serova M, de Gramont A, Hammel P, Raymond E \& Faivre S 2012 Resistance to targeted therapies in pancreatic neuroendocrine tumors (PNETs): molecular basis, preclinical data, and counteracting strategies. Targeted Oncology 7 173-181. (https://doi.org/10.1007/s11523-012-0229-6)

Tompkins WA 1999 Immunomodulation and therapeutic effects of the oral use of interferon-alpha: mechanism of action. Journal of Interferon and Cytokine Research 19 817-828. (https://doi. org/10.1089/107999099313325)

Touat M, Ileana E, Postel-Vinay S, André F \& Soria J-C 2015 Targeting FGFR signaling in cancer. Clinical Cancer Research 21 2684-2694. (https://doi.org/10.1158/1078-0432.CCR-14-2329)

Turner HE, Harris AL, Melmed S \& Wass JAH 2003 Angiogenesis in endocrine tumors. Endocrine Reviews 24 600-632. (https://doi. org/10.1210/er.2002-0008)
Ungefroren H, Sebens S, Seidl D, Lehnert H \& Hass R 2011 Interaction of tumor cells with the microenvironment. Cell Communication and Signaling 9 18. (https://doi.org/10.1186/1478-811X-9-18)

van Adrichem RCS, Hofland LJ, Feelders RA, De Martino MC, van Koetsveld PM, van Eijck CHJ, de Krijger RR, Sprij-Mooij DM, Janssen JAMJL \& de Herder WW 2013 Chromogranin A, Ki-67 index and IGF-related genes in patients with neuroendocrine tumors. Endocrine Connections 2 172-177. (https://doi.org/10.1530/EC-130052)

van Adrichem RCS, de Herder WW, Kamp K, Brugts MP, de Krijger RR, Sprij-Mooij DM, Lamberts SWJ, van Koetsveld PM, Janssen JAMJL \& Hofland LJ 2016 Effects of somatostatin analogs and dopamine agonists on insulin-like growth factor 2-induced insulin receptor isoform-a activation by gastroenteropancreatic neuroendocrine tumor cells. Neuroendocrinology 103 815-825. (https://doi. org $/ 10.1159 / 000444280)$

Vandamme T, Peeters M, Dogan F, Pauwels P, Van Assche E, Beyens M, Mortier G, Vandeweyer G, de Herder W, Van Camp G, et al. 2015 Whole-exome characterization of pancreatic neuroendocrine tumor cell lines BON-1 and QGP-1. Journal of Molecular Endocrinology $\mathbf{5 4}$ 137-147. (https://doi.org/10.1530/JME-14-0304)

Vikman S, Sommaggio R, De La Torre M, Oberg K, Essand M, Giandomenico V, Loskog A \& Totterman T 2009 Midgut carcinoid patients display increased numbers of regulatory $\mathrm{T}$ cells in peripheral blood with infiltration into tumor tissue. Acta Oncologica $\mathbf{4 8}$ 391-400. (https://doi.org/10.1080/02841860802438495)

Vitale G, de Herder WW, van Koetsveld PM, Waaijers M, Schoordijk W, Croze E, Colao A, Lamberts SWJ \& Hofland LJ 2006 IFN-beta is a highly potent inhibitor of gastroenteropancreatic neuroendocrine tumor cell growth in vitro. Cancer Research 66 554-562. (https://doi. org/10.1158/0008-5472.CAN-05-3043)

Vlodavsky I, Ilan N, Naggi A \& Casu B 2007 Heparanase: structure, biological functions, and inhibition by heparin-derived mimetics of heparan sulfate. Current Pharmaceutical Design 13 2057-2073. (https://doi.org/10.2174/138161207781039742)

Vlodavsky I, Beckhove P, Lerner I, Pisano C, Meirovitz A, Ilan N \& Elkin M 2012 Significance of heparanase in cancer and inflammation. Cancer Microenvironment 5 115-132. (https://doi. org/10.1007/s12307-011-0082-7)

von Marschall Z, Cramer T, Höcker M, Burde R, Plath T, Schirner M, Heidenreich R, Breier G, Riecken EO, Wiedenmann B, et al. 2000 De novo expression of vascular endothelial growth factor in human pancreatic cancer: evidence for an autocrine mitogenic loop. Gastroenterology 119 1358-1372. (https://doi.org/10.1053/ gast.2000.19578)

von Marschall Z, Scholz A, Cramer T, Schäfer G, Schirner M, Oberg K, Wiedenmann B, Höcker M \& Rosewicz S 2003 Effects of interferon alpha on vascular endothelial growth factor gene transcription and tumor angiogenesis. Journal of the National Cancer Institute $\mathbf{9 5}$ 437-448. (https://doi.org/10.1093/jnci/95.6.437)

von Wichert G, Jehle PM, Hoeflich A, Koschnick S, Dralle H, Wolf E, Wiedenmann B, Boehm BO, Adler G \& Seufferlein T 2000 Insulinlike growth factor-I is an autocrine regulator of chromogranin A secretion and growth in human neuroendocrine tumor cells. Cancer Research 60 4573-4581.

von Wichert G, Haeussler U, Greten FR, Kliche S, Dralle H, Böhm BO, Adler G \& Seufferlein T 2005 Regulation of cyclin D1 expression by autocrine IGF-I in human BON neuroendocrine tumour cells. Oncogene 24 1284-1289. (https://doi.org/10.1038/sj.onc.1208264)

Walter T, Hommell-Fontaine J, Gouysse G, Pourreyron C, Nejjari M, Villaume K, Causeret S, Hervieu V, Poncet G, Roche C, et al. 2011 Effects of somatostatin and octreotide on the interactions between neoplastic gastroenteropancreatic endocrine cells and endothelial cells: a comparison between in vitro and in vivo properties. Neuroendocrinology 94 200-208. (https://doi.org/10.1159/000328134)
C) 2018 Society for Endocrinology Published by Bioscientifica Ltd. Printed in Great Britain 
Wei S-C, Tsao P-N, Yu S-C, Shun C-T, Tsai-Wu J-J, Wu CHH, Su Y-N, Hsieh F-J \& Wong J-M 2005 Placenta growth factor expression is correlated with survival of patients with colorectal cancer. Gut $\mathbf{5 4}$ 666-672. (https://doi.org/10.1136/gut.2004.050831)

Welin S, Fjällskog ML, Saras J, Eriksson B \& Janson ET 2006 Expression of tyrosine kinase receptors in malignant midgut carcinoid tumors. Neuroendocrinology 84 42-48. (https://doi.org/10.1159/000096294)

Wimmel A, Wiedenmann B \& Rosewicz S 2003 Autocrine growth inhibition by transforming growth factor beta-1 (TGFbeta-1) in human neuroendocrine tumour cells. Gut 52 1308-1316. (https:// doi.org/10.1136/gut.52.9.1308)

Wong ST, Winchell LF, McCune BK, Earp HS, Teixidó J, Massagué J, Herman B \& Lee DC 1989 The TGF-alpha precursor expressed on the cell surface binds to the EGF receptor on adjacent cells, leading to signal transduction. Cell 56 495-506. (https://doi.org/10.1016/00928674(89)90252-3)

Wong C, Vosburgh E, Levine AJ, Cong L \& Xu EY 2012 Human neuroendocrine tumor cell lines as a three-dimensional model for the study of human neuroendocrine tumor therapy. Journal of Visualized Experiments 14 e4218. (https://doi.org/10.3791/4218)

Wulbrand U, Wied M, Zöfel P, Göke B, Arnold R \& Fehmann H 1998 Growth factor receptor expression in human gastroenteropancreatic neuroendocrine tumours. European Journal of Clinical Investigation 28 1038-1049. (https://doi. org/10.1046/j.1365-2362.1998.00397.x)

Wulbrand U, Remmert G, Zöfel P, Wied M, Arnold R \& Fehmann HC 2000 mRNA expression patterns of insulin-like growth factor system components in human neuroendocrine tumours. European Journal of Clinical Investigation 30 729-739. (https://doi. org/10.1046/j.1365-2362.2000.00700.x)

Wuttke M, Papewalis C, Jacobs B \& Schott M 2009 Identifying tumor antigens in endocrine malignancies. Trends in Endocrinology and Metabolism 20 122-129. (https://doi.org/10.1016/j.tem.2008.12.003)

Yao JC \& Phan A 2011 Overcoming antiangiogenic resistance. Clinical Cancer Research 17 5217-5219. (https://doi.org/10.1158/1078-0432. CCR-11-1219

Yao JC, Hassan M, Phan A, Dagohoy C, Leary C, Mares JE, Abdalla EK, Fleming JB, Vauthey JN, Rashid A, et al. 2008 One hundred years after 'carcinoid': epidemiology of and prognostic factors for neuroendocrine tumors in 35,825 cases in the United States. Journal of Clinical Oncology 26 3063-3072. (https://doi.org/10.1200/JCO.2007.15.4377)

Yao JC, Lombard-Bohas C, Baudin E, Kvols LK, Rougier P, Ruszniewski P, Hoosen S, St Peter J, Haas T, Lebwohl D et al. 2010 Daily oral everolimus activity in patients with metastatic pancreatic neuroendocrine tumors after failure of cytotoxic chemotherapy: a phase II trial. Journal of Clinical Oncology : Official Journal of the American Society of Clinical Oncology 28 69-76. (https://doi. org/10.1200/JCO.2009.24.2669)

Yao JC, Shah MH, Ito T, Bohas CL, Wolin EM, Van Cutsem E, Hobday TJ, Okusaka T, Capdevila J, de Vries EGE, et al. 2011 Everolimus for advanced pancreatic neuroendocrine tumors. New England Journal of Medicine 364 514-523. (https://doi.org/10.1056/ NEJMoa1009290)

Yao JC, Guthrie K, Moran C, Strosberg JR, Kulke MH, Chan JA, LoConte NK, McWilliams RR, Wolin EM, Mattar BI et al. 2015 SWOG S0518: Phase III prospective randomized comparison of depot octreotide plus interferon alpha-2b versus depot octreotide plus bevacizumab (NSC \#704865) in advanced, poor prognosis carcinoid patients (NCT00569127). ASCO Meeting Abstracts 334004.

Yao JC, Fazio N, Singh S, Buzzoni R, Carnaghi C, Wolin E, Tomasek J, Raderer M, Lahner H, Voi M, et al. 2016 Everolimus for the treatment of advanced, non-functional neuroendocrine tumours of the lung or gastrointestinal tract (RADIANT-4): a randomised, placebo-controlled, phase 3 study. Lancet 387 968-977. (https://doi. org/10.1016/S0140-6736(15)00817-X)

Yazdani S, Kasajima A, Tamaki K, Nakamura Y, Fujishima F, Ohtsuka H, Motoi F, Unno M, Watanabe M, Sato Y, et al. 2014 Angiogenesis and vascular maturation in neuroendocrine tumors. Human Pathology $\mathbf{4 5}$ 866-874. (https://doi.org/10.1016/j.humpath.2013.09.024)

Yu R 2016 Animal models of spontaneous pancreatic neuroendocrine tumors. Molecular and Cellular Endocrinology 421 60-67. (https://doi org/10.1016/j.mce.2015.08.004)

Yuge R, Kitadai Y, Shinagawa K, Onoyama M, Tanaka S, Yasui W \& Chayama K 2015 mTOR and PDGF pathway blockade inhibits liver metastasis of colorectal cancer by modulating the tumor microenvironment. American Journal of Pathology 185 399-408. (https://doi.org/10.1016/j.ajpath.2014.10.014)

Zhang PJ, Furth EE, Cai X, Goldblum JR, Pasha TL \& Min KW 2004 The role of beta-catenin, TGF beta 3, NGF2, FGF2, IGFR2, and BMP4 in the pathogenesis of mesenteric sclerosis and angiopathy in midgut carcinoids. Human Pathology 35 670-674. (https://doi.org/10.1016/j. humpath.2003.12.010)

Zhou Y, Wang S, Yue B-G, Gobl A \& Oberg K 2002 Effects of interferon alpha on the expression of p21cip1/waf1 and cell cycle distribution in carcinoid tumors. Cancer Investigation 20 348-356. (https://doi. org/10.1081/CNV-120001180)

Received in final form 27 July 2018

Accepted 2 July 2018

Accepted Preprint published online 2 July 2018 (c) 2018 Society for Endocrinology Published by Bioscientifica Ltd. Printed in Great Britain 